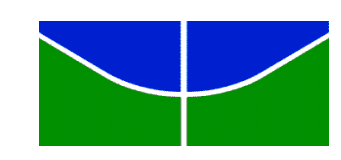

UNIVERSIDADE DE BRASÍLIA

FACULDADE DE AGRONOMIA E MEDICINA VETERINÁRIA CAMPUS DARCY RIBEIRO

\title{
ANÁLISE DE IMAGENS NA AVALIAÇÃO DO VIGOR DE SEMENTES DE SOJA
}

ERICH BARROS BRANDANI

DISSERTAÇÃO DE MESTRADO EM AGRONOMIA

BRASÍLIA/DF

Fevereiro/2017 


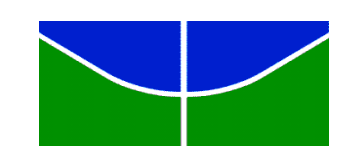

UNIVERSIDADE DE BRASÍLIA

FACULDADE DE AGRONOMIA E MEDICINA VETERINÁRIA

CAMPUS DARCY RIBEIRO

\section{ANÁLISE DE IMAGENS NA AVALIAÇÃO DO VIGOR DE SEMENTES DE SOJA}

ERICH BARROS BRANDANI

ORIENTADOR: Dra. NARA OLIVEIRA SILVA SOUZA CO-ORENTADOR: Dr. NILSON MATHEUS MATTIONI

DISSERTAÇÃO DE MESTRADO EM AGRONOMIA

PUBLICAÇÃO: 128/2017

BRASÍLIA/DF

Fevereiro/2017 


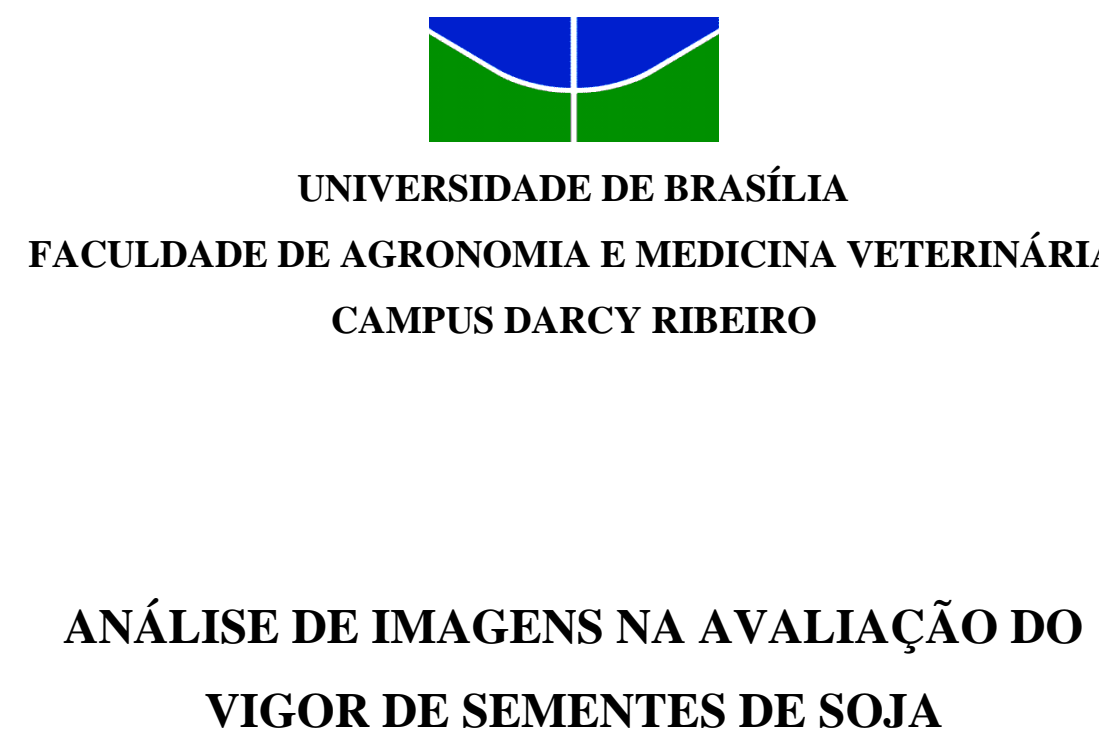

ERICH BARROS BRANDANI

DISSERTAÇ̃̃O DE MESTRADO SUBMETIDA AO PROGRAMA DE PÓSGRADUAÇÃ̃O EM AGRONOMIA, COMO PARTE DOS REQUISITOS NECESSÁRIOS À OBTENÇÃO DO GRAU DE MESTRE/DOUTOR EM AGRONOMIA.

APROVADA POR:

NARA OLIVEIRA SILVA SOUZA Dra. Professora Adjunto UnB - FAV, CPF: 033.300.726-36 Email: narasouza@unb.br (Orientadora)

MARCELO FAGIOLI Dr. Professor Adjunto UnB - FAV, CPF: 729.409.306-78 Email: mfagioli@unb.br

TAISLENE BUTARELLO RODRIGUES DE MORAIS Dra. Professora Adjunto UnB FAV, CPF: 269.394.408-28 Email: taislene@gmail.com 


\section{FICHA CATALOGRÁFICA}

Brandani, Erich Barros

Análise de imagens na avaliação do vigor de sementes de soja. / Erich Barros Brandani; orientação de Nara Oliveira Silva Souza - Brasília, 2017. $54 \mathrm{p}$.

Dissertação de Mestrado (M) - Universidade de Brasília/Faculdade de Agronomia e Medicina Veterinária, 2017.

1. Glycine max. 2. Análise de imagens. 3. Vigor de sementes. Souza, N. O. S. Dra.

\section{REFERÊNCIA BIBLIOGRÁFICA}

BRANDANI, E. B. Análise de imagens na avaliação do vigor de sementes de soja. Brasília: Faculdade de Agronomia e Medicina Veterinária, Universidade de Brasília, 2017, 54p. Dissertação de Mestrado.

\section{CESSÃO DE DIREITOS}

AUTOR: Erich Barros Brandani

TÍTULO: Análise de imagens na avaliação vigor de sementes de soja.

GRAU: Mestre

ANO: 2017

É concedida à Universidade de Brasília de Brasília permissão para reproduzir cópias desta dissertação de mestrado para única e exclusivamente propósitos acadêmicos e científicos. $\mathrm{O}$ autor reserva para si os outros direitos autorais, de publicação. Nenhuma parte desta dissertação de mestrado pode ser sem a autorização por escrito do autor. Citações são estimuladas, desde que citada à fonte.

Nome: Erich Barros Brandani

Email: erich_bb@hotmail.com 


\section{AGRADECIMENTOS}

À minha mãe, Maria das Dores Souza Barros, por todo o carinho e amor que sempre me dedicou, trazendo alegria e leveza à minha vida.

Ao meu pai, Hamilton Brandani, por todo o apoio e segurança, por acreditar em mim e possibilitar que mais uma conquista fosse alcançada.

Ao meu irmão Yuri Barros Brandani, meu melhor amigo, que me dá forças pra enfrentar as situações da vida e vencer.

À Andiara Valloni dos Santos, uma pessoa muito especial, que compartilhou comigo momentos bons e ruins, que me fez aprender independente de erros e acertos, engrandecendo meu ser e me tornando uma pessoa melhor.

À minha orientadora, Nara Oliveira Silva Souza, minha mãe na universidade, fonte de conhecimento e sabedoria, que confiou em mim e possibilitou a realização de um sonho profissional.

Ao meu Co-Orientador, Nilson Mattioni, pela confiança em meu trabalho e por prover todas as ferramentas necessárias para que o nível de qualidade dos experimentos fosse o maior possível.

A toda a equipe da empresa DuPont ${ }^{\circledR}$ - Divisão Pioneer Sementes, por todo suporte e dedicação, em especial ao Ariclenes, Tatiana, Rodrigo, Suzana e Juliana por me acolherem com todo o respeito e profissionalismo.

Ao Fabiano Vilela da empresa Tbit Tecnologia e Sistemas, um excelente profissional que se tornou também um amigo.

À Universidade de Brasília (UnB), Programa de pós-graduação em agronomia e todos seus professores pelo apoio institucional.

À Coordenação de Aperfeiçoamento de Pessoal de Nível Superior (CAPES), pela bolsa de estudos, ao CNPq e à Fundação de Apoio à Pesquisa do Distrito Federal (FAPDF) pelo apoio financeiro.

A todos os meus amigos, em especial ao Lucas Mattar, pelo apoio, pela força e pela amizade sincera.

À minha família, base de todo o carinho e amor que existe em mim. 


\section{LISTA DE ILUSTRAÇÕES}

Figura 1 - Modelos Cielab, HSV e YCbCr para calibração da cor de fundo pelo software GroundEye, UnB, Brasília-DF, Brasil, 2017 .17

Figura 2 - Exemplo de correção da imagem das plântulas feito no software GroundEye: a) plântula sem correção e b) plântula com correção, UnB, Brasília-DF, Brasil, 2017....18

Figura 3 - Configuração de análise utilizada na análise de imagens de plântulas de soja pelo software GroundEye, UnB, Brasília-DF, Brasil, 2017.........................................................30

Tabela 1 - Resultados médios obtidos na avaliação qualidade fisiológica em sementes de soja de oito lotes da variedade 1. Brasília-DF, 2017...............................................................26

Tabela 2 - Resultados médios obtidos na avaliação da qualidade fisiológica de sementes de soja de oito lotes da variedade 2. Brasília-DF, 2017.

Tabela 3 - Teste de envelhecimento acelerado e análise de imagem das plântulas de soja dos oito lotes da variedade 1 pelo GroundEye................................................................................31

Tabela 4 - Resultado médio do comprimento de plântula e raiz de oito lotes de sementes de soja da variedade 1, realizados com medição manual e pelo GroundEye. Brasília-DF,

Tabela 5 - Teste de envelhecimento acelerado e análise de imagem das plântulas de soja dos oito lotes da variedade 2 pelo GroundEye. Brasília-DF, 2017

Tabela 6 - Resultado médio do comprimento de plântula e raiz de oito lotes de sementes de soja da variedade 2. Brasília-DF, 2017. 


\section{SUMÁRIO}

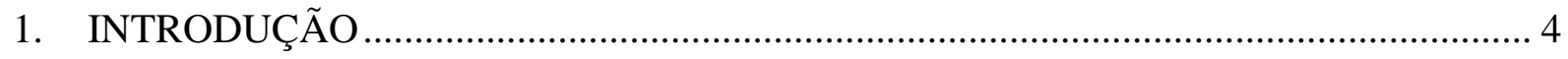

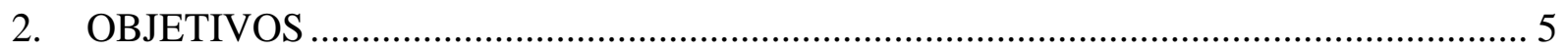

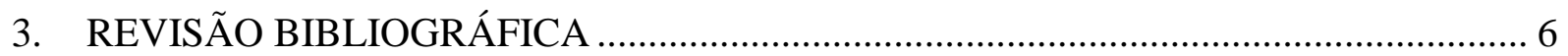

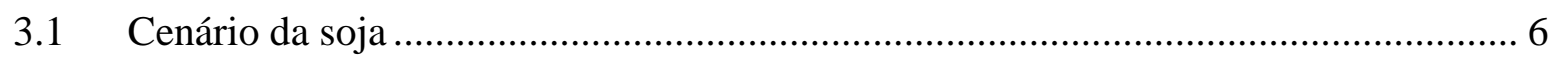

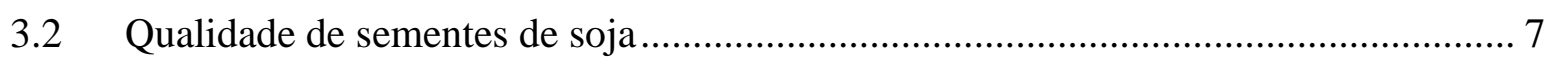

3.2.1 Testes de vigor em sementes................................................................ 8

3.3 Análise de imagens..................................................................................... 12

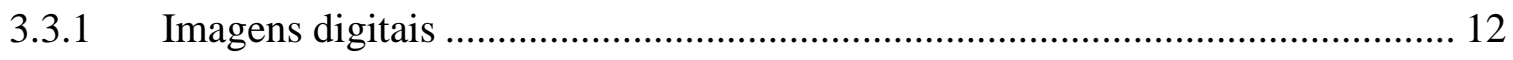

3.3.2 Análise de imagens de plântulas ..................................................................... 14

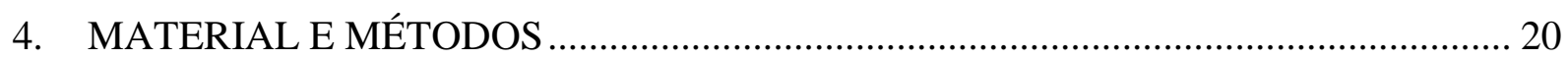

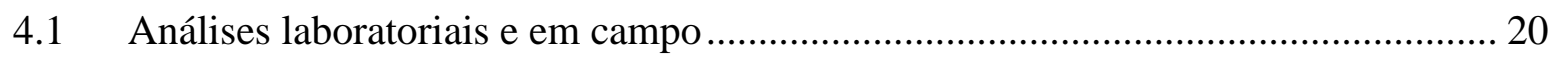

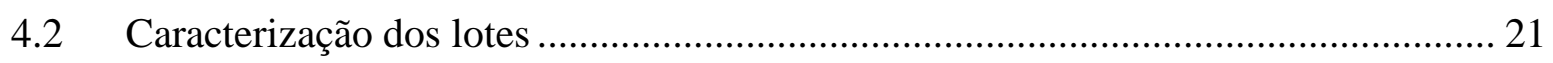

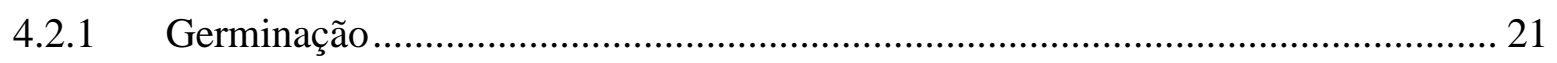

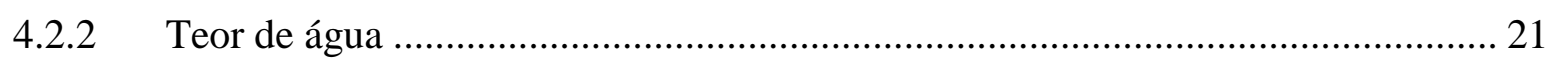





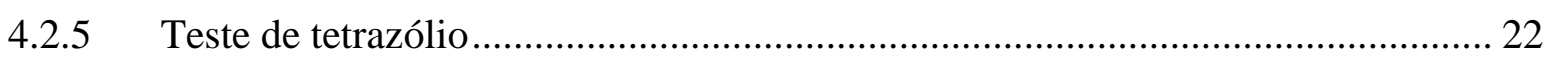

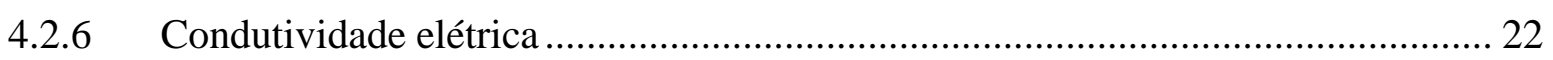

4.2.7 Emergência de plântulas em campo …………………………………………... 23

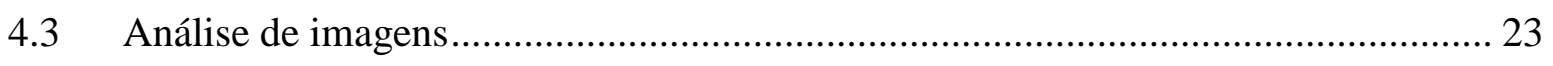



4.3.2 Captura de imagens .................................................................................. 24

4.3.3 Calibração automática ................................................................................... 24

4.10.4 Reanálise de imagens................................................................................ 25

4.4 Delineamento experimental e análise estatística ....................................................... 25

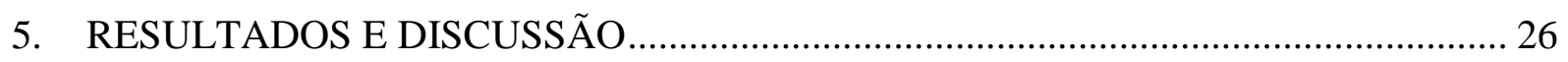

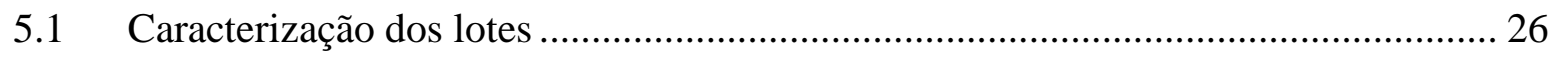

5.2 Análise de imagens...................................................................................... 30

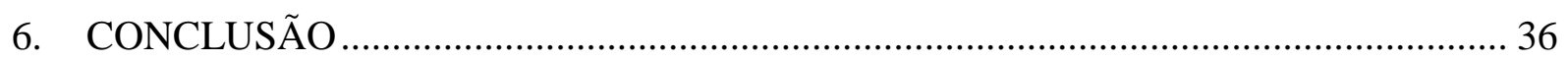

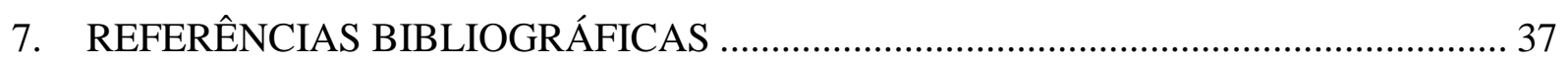






\section{RESUMO}

A análise de imagens de plântulas vem sendo estudada com o objetivo de minimizar as limitações existentes nos testes tradicionais, sendo uma técnica com amplo potencial de utilização no controle de qualidade de sementes de diversas culturas. O GroundEye é um equipamento que pode ser utilizado na avaliação da qualidade fisiológica de sementes. $\mathrm{O}$ objetivo foi adequar uma metodologia de análise de imagens de plântulas de soja pelo GroundEye, bem como verificar a potencialidade de utilização deste equipamento na avaliação do vigor de sementes de soja. Foram utilizados oito lotes de duas variedades de soja caracterizados pelos testes de germinação, envelhecimento acelerado, teste de frio, tetrazólio, condutividade elétrica e emergência de plântulas em campo. Foi realizada análise de imagens das plântulas de soja pelo software GroundEye sem correção manual e os resultados comparados com as medições manuais e o teste de vigor de envelhecimento acelerado. A caracterização mostrou que os lotes das duas variedades apresentavam diferença quanto à qualidade fisiológica. A avaliação de vigor realizada pelo envelhecimento acelerado e o índice de vigor do GroundEye foi igual na comparação dos lotes de soja. O mesmo foi verificado com a comparação da medição manual e a do GroundEye quanto ao comprimento de plântula e raiz. A avaliação do vigor de sementes de soja por meio da análise de imagem com o software GroundEye pode ser realizada em plântulas obtidas em semeadura em papel de germinação, a temperatura de $25{ }^{\circ} \mathrm{C}$ com avaliação ao terceiro dia, sem necessidade de correção da imagem das plântulas. O GroundEye demonstrou ser um equipamento promissor na avaliação do vigor de sementes de soja, podendo ser adotado como teste complementar no controle de qualidade de empresas produtoras de sementes.

Palavras-chave: Glycine max L., qualidade fisiológica, software GroundEye. 


\begin{abstract}
The analysis of seedling images has been studied with the objective of minimizing the existing limitations in the traditional tests, being a technique with wide potential of use in the quality control of seeds of diverse cultures. GroundEye is an equipment that can be used to evaluate the physiological quality of seeds. The objective was to adapt a methodology of soybean seedlings image analysis by GroundEye, as well as verify the potential use of this equipment in the evaluation of soybean seed vigor. Eight lots of two varieties of soybean were used, characterized by the tests of germination, accelerated aging, cold test, tetrazolium, electrical conductivity and emergence of field seedlings. Soybean seedlings were analyzed by the GroundEye software without manual correction and the results compared with the manual measurements and the accelerated aging vigor test. The characterization showed that the lots of the two varieties had differences in the physiological quality. The vigor evaluation performed by accelerated aging and GroundEye's vigor index was the same in the comparison of soybean lots. The same was verified by comparing the manual measurement and the GroundEye measurement for seedling and root length. The evaluation of the vigor of soybean seeds by means of the image analysis with the software GroundEye can be carried out in seedlings obtained in sowing in germination paper, the temperature of $25{ }^{\circ} \mathrm{C}$ with evaluation in the third day, without need of correction of the image of the seedlings. GroundEye has been shown to be a promising equipment in the evaluation of the vigor of soybean seeds, and can be adopted as a complementary test in the quality control of seed companies.
\end{abstract}

Key words: Glycine max L., physiological quality, GroundEye software. 


\section{INTRODUÇÃO}

A soja [Glycine $\max (\mathrm{L}$.) Merrill] é a cultura agrícola que mais cresceu nas últimas três décadas no Brasil. Sua expansão para o Centro-Oeste nos levou a um patamar de crescimento nunca visto antes, nos tornando o segundo maior produtor mundial e o maior exportador. Tal crescimento é reflexo da adoção de boas práticas agrícolas, técnicas de manejo e devido aos avanços no melhoramento genético onde a utilização de sementes de alta qualidade é destaque por ser a base para o sucesso da produção.

A qualidade das sementes é garantida no processo de certificação, onde são requeridos padrões mínimos de pureza física e de germinação em sua produção. O teste de germinação é realizado visando a avaliação do potencial fisiológico de lotes de sementes, porém, por ser um teste realizado em condições ideais de germinação, nem sempre os resultados obtidos refletem o potencial do lote em condições de campo. Outros testes são realizados visando a complementação dos resultados obtidos no teste de germinação. Testes de vigor são muito utilizados por serem mais sensíveis, identificando estágios de deterioração menos avançados, facilitando o manuseio de lotes de sementes quanto ao seu destino ou descarte, além de evidenciar o comportamento das sementes em situações específicas como a secagem, beneficiamento e armazenamento, auxiliando na tomada de decisão durante todas as etapas da produção das sementes.

A busca por testes rápidos, que geram resultados representativos da qualidade das sementes é uma constante preocupação das empresas produtoras, onde o tempo para a execução dos testes têm se tornado um fator limitante. Além do tempo, a subjetividade presente na avaliação de tais testes tem sido foco de estudos que visam solucionar tais problemas.

Técnicas dentro da área de análise de imagens vem sendo estudadas para a avaliação da qualidade física e fisiológica de sementes visando minimizar as limitações existentes nos testes tradicionais. Sako et al. (2001) desenvolveram na Universidade Estadual de Ohio OSU, nos Estados Unidos, um sistema de avaliação de vigor (SVIS - Seed Vigor Image System) que, através de imagens digitais capturadas por um scanner, determina o vigor das sementes. Inicialmente o SVIS foi utilizado na avaliação do vigor de sementes de alface, posteriormente estudos verificaram a utilização bem sucedida do software para diversas espécies, tais como milho, trigo, amendoim, girassol, soja, pepino, melão e crotalária. 
No Brasil, a empresa Tbit Tecnologia e Sistemas desenvolveu um sistema semelhante ao SVIS, denominado GroundEye, o qual possui diversas utilidades, dentre elas a avaliação da qualidade física e fisiológica de sementes. Tal avaliação é feita por meio da análise de imagens de alta resolução obtidas pelo próprio equipamento, que permitem extrair informações de cor, textura e geometria, servindo como parâmetro para o fornecimento dos índices de crescimento, uniformidade e vigor de plântulas.

O GroundEye é um equipamento promissor para a avaliação do potencial fisiológico de sementes de soja, porém não existem pesquisas que comprovem sua eficiência para tal finalidade

\section{OBJETIVOS}

\subsection{Objetivo geral}

Adequar uma metodologia de análise de imagens de plântulas de soja pelo GroundEye, bem como verificar a potencialidade de utilização deste equipamento na avaliação do vigor de sementes de soja.

\subsection{Objetivos específicos}

Realizar comparação entre a avaliação realizada pelo teste de envelhecimento acelerado e o índice de vigor do GroundEye.

Comparar os resultados da medição manual do comprimento de plântulas e raiz com a medição realizada pelo GroundEye.

Verificar a eficiência do software GroundEye na avaliação do vigor de sementes de soja a partir de imagens de plântulas provenientes do teste de germinação ao terceiro dia e a sua possível aplicação como um teste complementar no controle de qualidade de empresas produtoras de sementes. 


\section{REVISÃO BIBLIOGRÁFICA}

\subsection{Cenário da soja}

O consumo de soja vem de um cenário de crescimento constante nos últimos anos, sendo impulsionado pelo aumento da população mundial e do poder aquisitivo das pessoas, principalmente de países em desenvolvimento, como o Brasil, China e Índia (SEAB, 2013). A China, além de centro de origem da cultura, é o maior consumidor de soja do mundo, sendo responsável por mais de $60 \%$ da demanda mundial e mais de $70 \%$ da exportação de soja Brasileira. De acordo com o levantamento do consumo mundial de soja feito pelo Departamento de Agricultura dos Estados Unidos (USDA) para a safra de 2015/2016, a china segue líder com o consumo recorde de 95 milhões de toneladas. Para este mesmo período, a produção mundial representa um recorde de 313,5 milhões de toneladas, sendo os principais produtores Estados Unidos com 106,1 milhões de toneladas, Brasil com 96,5 milhões de toneladas e Argentina com 56,8 milhões de toneladas, que juntos totalizam mais de $81 \%$ da produção mundial. No que se refere a exportação mundial de soja, o Brasil é primeiro no Rank com um total de 50 milhões exportados na safra de 2014/2015 e obtendo crescimento de $9 \%$ para a safra de 2015/2016, chegando aos 54,4 milhões de toneladas exportadas (USDA, 2017).

O Brasil tem prospecção de crescimento para os próximos anos e um dos principais motivos é o fato de ser um dos poucos países que ainda possuem fronteiras agrícolas a serem exploradas. A expansão da área cultivada no país é proveniente não só da abertura de áreas novas, mas também pela conversão de áreas ocupadas pela pecuária extensiva em lavouras (MENEGHELLO; PESKE, 2013).

Ao se fazer a análise da área cultivada com soja no Brasil, vemos que houve uma expansão da cultura do Sul para o Centro-Oeste, onde o processo de migração ocorreu primeiramente para regiões do estado de Santa Catarina e do Paraná, e posteriormente para os estados do Centro-Oeste. Tal processo de migração da cultura da soja teve início na década de 1960 e atualmente consolida o estado do Mato Grosso como o principal produtor de soja, responsável por $27 \%$ da produção nacional. Tal expansão só foi possível graças aos trabalhos realizados pelos programas de melhoramento, que desenvolveram cultivares adaptadas as condições de regiões de baixa latitude (MENEGHELLO; PESKE, 2013). 
De acordo com o levantamento feito pela Companhia Nacional de Abastecimento (CONAB) a área estimada para o cultivo de grãos no Brasil para a safra de 2015/16 foi de 58,3 milhões de hectares, sendo $0,5 \%$ superior à safra anterior. Dentro deste valor, a soja foi destaque ocupando mais de $57 \%$ da área utilizada para o cultivo de grãos obtendo o valor de 33,2 milhões de hectares plantados, demonstrando um crescimento de $3,6 \%$ em relação à safra anterior (CONAB, 2017).

Proporcionalmente durante os anos, o aumento da produção foi maior do que a área plantada, evidenciando o incremento da produtividade. O levantamento feito pela CONAB para a safra de 2015/16 indica uma produtividade de $2.870 \mathrm{~kg} / \mathrm{ha}$ com expectativa de crescimento de $7 \%$ para a safra de $2016 / 17$, onde se espera alcançar produtividades em torno de $3072 \mathrm{~kg} / \mathrm{ha}$. A adoção de boas práticas agrícolas, cultivares melhoradas e tecnologia de ponta é responsável pelo alcance de altas produtividades para diversas culturas graníferas no Brasil, tendo destaque a soja e o milho.

\subsection{Qualidade de sementes de soja}

Dentre as diversas práticas de manejo da cultura da soja, que são implantadas na lavoura visando altas produtividades, a utilização de sementes de qualidade é uma das mais importantes, sendo considerada a base para o sucesso da atividade. As sementes são responsáveis por expressar o potencial genético de produtividade, resistência ou tolerância a estresses bióticos ou abióticos, além de conferir atributos de qualidade física, fisiológica e sanitárias a quem as utiliza corretamente, garantindo assim, um desempenho agronômico não encontrado com a utilização de grãos para semeadura (KRZYZANOWSKY et al., 2008).

Morfologicamente, a semente é idêntica ao grão comercial, entretanto, semente é aquela produzida com finalidade de semeadura, sob cuidados especiais. O processo de produção de sementes de qualidade exige, além de um amplo e rigoroso sistema de controle de qualidade interno por parte das empresas produtoras, o cumprimento de leis e normas estabelecidas pelo Ministério da Agricultura e outros mecanismos reguladores, os quais determinam padrões mínimos de qualidade e controle do processo produtivo a fim de se garantir uma produção certificada de sementes.

$\mathrm{Na}$ certificação de sementes são requeridos padrões mínimos de pureza física e de germinação, porém em um cenário competitivo, em que a qualidade é um fator imprescindível 
e regulador de mercado, as empresas produtoras não se prendem somente a estes requisitos. Tanto para sementes de soja certificadas (C1 e C2) e não certificadas (S1 e S2), a porcentagem de germinação e pureza mínima requeridas para sua comercialização é de $80 \%$ e 99\%, respectivamente (BRASIL, 2013). Apesar deste ser o mínimo requerido, muitas empresas estipulam valores de germinação muito acima disto, visando a garantia da qualidade das sementes produzidas. Tais empresas possuem um controle de qualidade extremamente rigoroso, que visa o acompanhamento e a aferição da qualidade em todas as etapas do processo de produção e para isto, são feitos uma série de testes prescritos nas Regras para Análise de Sementes (RAS) e outros possíveis testes baseados em outras metodologias.

O teste de germinação é um teste bastante utilizado para a avaliação da qualidade fisiológica de lotes de sementes, porém, por ser um teste realizado em condições ideais de germinação, nem sempre os resultados obtidos refletem o potencial do lote em condições de campo (OHLSON et al., 2010). Tal teste é realizado com o objetivo de se obter informação de valor prático sobre um determinado lote de sementes, onde se torna mensurável seu potencial de germinação podendo ser associado à sua qualidade fisiológica. Outros testes são realizados visando complementar as informações obtidas pelo teste de germinação. Tais testes têm por princípio simular o potencial de emergência em campo sob condições adversas, os chamados testes de vigor.

\subsubsection{Testes de vigor em sementes}

De acordo com a definição adotada pela Association of Official Seed Analysts, "vigor de sementes compreende aquelas propriedades que determinam o potencial para uma emergência rápida e uniforme e para o desenvolvimento de plântulas normais sob uma ampla faixa de condições ambientais" (AOSA, 1983). O vigor de uma semente esta relacionado à sua eficiência em desempenhar seu papel de emergir rápida e uniformemente, e desenvolverse em condições de campo favoráveis ou não, estando este fator intimamente ligado não só com a produtividade como também a qualidade e padronização do produto colhido.

Isely (1957) classificou os testes de vigor em diretos e indiretos. Os testes diretos tem como objetivo avaliar o desempenho das sementes perante uma ampla gama de condições ambientais, muitas vezes adversas ao desenvolvimento da semente, sendo esta a realidade de campo. Os testes indiretos consistem em avaliar características físicas, fisiológicas ou biológicas, que de forma indireta estão relacionadas ao vigor das sementes. 
Com o avanço dos estudos sobre os testes de vigor e com um entendimento maior sobre os métodos de avaliação e classificação do vigor de sementes, se tornou possível verificar algumas lacunas na classificação dos testes de vigor feita por Isely (1957), pois alguns testes possuíam características que os encaixava nas duas categorias propostas, como os testes baseados no crescimento das plântulas, que são realizados tanto em laboratórios quanto em condições de campo. Sendo assim, em busca de uma classificação mais completa e precisa, McDonald (1975) propôs a divisão dos testes de vigor em quatro categorias, sendo testes físicos, físiológicos, bioquímicos e de resistência. Os testes classificados como físicos são os que avaliam características físicas e aspectos da morfologia da semente com relação ao vigor. Como exemplo de testes físicos temos os testes de raios-X, tamanho de semente e peso unitário de sementes. Já os testes fisiológicos são os que procuram avaliar o desempenho de atividades fisiológicas que estão correlacionadas ao vigor das sementes utilizadas. A classificação do vigor das plântulas, a primeira contagem de germinação e o teste de velocidade de germinação de plântulas são exemplos de testes fisiológicos. Os testes bioquímicos avaliam modificações bioquímicas associadas ao vigor das sementes. Como exemplo de teste bioquímico temos os testes de condutividade elétrica e tetrazólio. Como última categoria estão os testes de resistência, que consistem na avaliação do desempenho das sementes sobre condições extremas de temperatura e umidade. O teste de frio e de envelhecimento acelerado são exemplos desta categoria.

Testes baseados em métodos rápidos que geram informações eficientes e de valor prático, auxiliando principalmente na tomada decisão quanto às operações de colheita, processamento e comercialização das sementes produzidas são os mais visados (DIAS; MARCOS FILHO, 1995; BITTENCOURT et al., 2012). Para a avaliação do vigor de sementes de soja, vários testes têm sido recomendados, dentre eles se destacam o de envelhecimento acelerado, de frio, condutividade elétrica, crescimento de plântulas e classificação do vigor de plântulas (VIEIRA et al., 2003).

O teste de envelhecimento acelerado possui diversas metodologias, onde os fatores de variação entre elas são a temperatura e o tempo de acondicionamento das caixas tipo "gerbox" em câmara BOD. Tal teste tem como princípio expor a sementes de um determinado lote a condições de alta temperatura e umidade, visando a avaliação posterior do desempenho das mesmas, o qual refletirá seu potencial de armazenamento, além de estar diretamente relacionado com seu vigor (AOSA, 2009).

Estudos comprovam o sucesso no emprego do teste de envelhecimento acelerado na 
aferição do vigor de diversas culturas, dentre elas a cultura da soja (DUTRA; VIEIRA, 2004), feijão (MARCOS-FILHO, 1999), trigo (OHLSON et al., 2010), arroz (WRASSE et al., 2009), milho (BITTENCOURT; VIEIRA, 2006), aveia preta (SOUZA et al., 2009), sorgo (VANZOLINI; CARVALHO, 2002), nabo forrageiro (NERY et al., 2009), entre outras.

Kappes et al. (2009) verificaram o efeito da dessecação em pré-colheita no desempenho fisiológico de sementes de soja, observando que, entre os testes utilizados, o de envelhecimento acelerado foi o mais sensível para indicar diferenças de qualidade das sementes.

O teste de frio, que também visa a simulação de condições de estresse para as sementes de um determinado lote, tem como objetivo avaliar o potencial físiológico das sementes em germinarem sob condições de baixa temperatura do solo e alta umidade, sendo considerado um teste de resistência, ou seja, o lote de sementes que melhor resistir às condições adversas é considerado mais vigoroso (MIGUEL; CÍCERO, 1999).

Seguindo uma certa lógica, se houver semelhança na comparação entre os resultados do teste de frio e o de germinação, há grande possibilidade desse lote de sementes apresentar capacidade para germinar sob ampla variação de condições de umidade e temperatura do solo (CICERO; VIEIRA, 1994).

Atualmente o teste de frio é bastante utilizado dentro do controle de qualidade de empresas produtoras de sementes, porém, tal teste demanda uma quantidade de tempo relativamente grande para a sua conclusão. Para a soja, o teste é conduzido em substrato composto de uma mistura de terra cultivada anteriormente com soja e areia, sendo que após a semeadura, as sementes são mantidas por cinco dias em câmara fria a $10^{\circ} \mathrm{C} \mathrm{e}$, posteriormente, por sete dias em câmaras de crescimento a $25^{\circ} \mathrm{C}$, quando então se procede a verificação dos resultados (MARCOS-FILHO, 2015).

Outro teste bastante utilizado para a verificação do vigor de sementes de soja é o de condutividade elétrica, sendo um teste que gera resultados confiáveis com relação ao vigor de um determinado lote de semente, além de ser relativamente rápido, fornecendo resultados em 24 horas (VIEIRA et al., 2002).

Para o teste de condutividade elétrica o vigor de um determinado lote de sementes é avaliado indiretamente através da determinação da condutividade elétrica da solução de embebição das sementes. Quanto menor o valor correspondente à liberação de exsudatos na solução de embebição das sementes, maior o vigor das mesmas, revelando menor intensidade de desorganização dos sistemas membranais das células (VIEIRA et al., 2002). 
Outro teste bioquímico que tem sido muito utilizado para a cultura da soja é o teste de tetrazólio. Tal teste é uma ótima alternativa na avaliação do vigor e viabilidade de sementes pela qualidade e rapidez em sua determinação, permitindo obter resultados, de modo geral, em menos de 24 horas (DELOUCHE et al., 1976; FRANÇA-NETO et al., 1988; COSTA; MARCOS-FILHO, 1994).

Além de avaliar a viabilidade e o vigor dos lotes de sementes, o teste de tetrazólio fornece o diagnóstico das possíveis causas da perda de qualidade. Sendo verificado a presença de danos mecânicos, deterioração por umidade e danos por percevejos, além de danos de secagem, estresse hídrico e geada.

Gazzoni (1998) utilizou o teste de tetrazólio para avaliar o efeito da população de percevejos na produtividade e na qualidade de sementes de soja, verificando que o teste de tetrazólio foi eficiente na mensuração dos danos por percevejo nas sementes de soja.

Giurizatto et al. (2003) também utilizaram o teste de tetrazólio para estimar a qualidade de sementes de soja, dos cultivares EMBRAPA-64, EMBRAPA-4, BR-16, FTAbyara e IAC-100, e das linhagens, BRD-9527, BRD-9561, BRD-9507 e BRD-9502, produzidas em Dourados, Mato Grosso do Sul, e colhidas 15 dias após o ponto de maturidade fisiológica. Os autores verificaram que este teste foi eficiente para estimar o vigor das sementes de cada um dos lotes de sementes estudados.

O teste de tetrazólio pode ser aplicado em diversas etapas do sistema de produção, permitindo identificar os problemas e possibilitando que ações corretivas sejam adotadas, obtendo assim sementes de alta qualidade, além de possibilitar a correlação de seus resultados com outros testes.

Testes de vigor baseados no desempenho de plântulas são de extrema importância para a avaliação do vigor de lotes de sementes (HOFFMASTER et al., 2003). Dentre estes testes, os testes de classificação do vigor de plântulas e o de crescimento de plântulas são muito utilizados para a cultura da soja, podendo ser realizados tanto em campo quanto em laboratório sob condições controladas. Quando realizados sob condições controladas tais testes podem ser feitos em conjunto com o teste de germinação visto que possuem a mesma metodologia para sua confecção (BRASIL, 2009).

O teste de classificação do vigor da plântulas consiste na classificação das plântulas provenientes do teste de germinação em normais fortes, normais fracas e anormais, de acordo os parâmetros definidos por Nakagawa (1999) para a cultura da soja. Os lotes de sementes que possuírem porcentagem maior de plântulas normais fortes serão considerados mais 
vigorosos, ou seja, terão maiores possibilidades de emergir e produzir plantas normais em condições adversas de campo.

O teste de crescimento de plântulas consiste na determinação do comprimento médio das plântulas normais, onde, para soja, toma-se a medida da extremidade da raiz até a inserção dos cotilédones. Segundo Nakagawa (1999) o comprimento médio da plântula é obtido somando as medidas tomadas de cada plântula normal, em cada repetição, e dividindo, a seguir, pelo número de plântulas normais mensuradas. Os resultados são expressos $\mathrm{em} \mathrm{cm}$, com uma casa decimal. Como conclusão para tal teste admite-se que as amostras que apresentam os maiores valores médios são as mais vigorosas (NAKAGAWA, 1999). De acordo com Dan et al. (1987), isso ocorre devido ao fato das sementes mais vigorosas originarem plântulas com maior taxa de crescimento, em função da maior translocação das reservas dos tecidos de armazenamento para o crescimento do eixo embrionário.

Para a realização do teste de comprimento de plântulas não são necessários analistas e equipamentos especializados, sendo um teste relativamente simples, porém as medições realizadas no teste são feitas manualmente, demandando tempo e estando sujeitas à variações dentre analistas (DORNELAS et al., 2005). Tendo em vista a grande demanda de tempo e a subjetividade proveniente das variações entre os possíveis analistas do teste, uma alternativa que solucionaria tais problemas seria a automatização deste processo a partir do processamento computadorizado de imagens (HOFFMASTER et al., 2003) que, além de tornar o teste mais rápido, traria também resultados mais precisos (MARCOS-FILHO et al., 2015).

\subsection{Análise de imagens}

\subsubsection{Imagens digitais}

Toda imagem digital em duas dimensões (2D) obedece a um sistema de coordenadas espaciais XY, onde são reconhecidos pontos, unidades discretas com atributos numéricos que denotam propriedades como a cor, sendo a representação da intensidade luminosa uma função $\mathrm{f}(\mathrm{x}, \mathrm{y})$ com valor proporcional ao brilho ou, no caso de imagens monocromáticas, níveis de cinza (GONZALEZ; WOODS, 2010).

Uma imagem digital pode ser comparada a uma matriz, onde unidades discretas formadoras da imagem se dispõem em linhas e colunas, sendo que índices identificam um 
ponto na imagem e o seu correspondente atributo. As unidades discretas, formadoras da imagem são ditas elementos da imagem, do inglês "Pictures Elements" (CÍCERO et al., 1998).

A análise de imagem digital consiste no reconhecimento da cena para a geração de características dimensionais, como áreas ou comprimentos de objetos, ou atributos, como padrões de cores e texturas, e a sua mensuração através de métodos de contagem ou frequência dos elementos formadores da imagem denominados "pixels", do inglês "pictures elements" que foi abreviado para "pics els" e então fundido gerando o termo "pixels". Para o processamento de imagens digitais foram desenvolvidos algoritmos de computação, que devidamente sistematizados são a base para a análise de imagens digitais, podendo esta ser caracterizada pelo arquivamento de dados e ou comparação de padrões (CÍCERO et al., 1998)

Utilizando a análise de imagens, Gunasekaran et al. (1988) avaliaram danos provocados por patógenos em sementes de soja e de milho. McDonald e Chen (1990) relataram que, além de sua utilização em agrometeorologia, a análise de imagens vem sendo adaptada para a análise de formas e dimensões de objetos contidos em uma cena. Vooren e Heijden (1993), utilizaram a análise de imagens digitais para avaliar características externas, como tamanho e forma, de bulbos e tubérculos.

Para se ter o processamento da imagem digital quatro etapas são necessárias: captura da imagem, pré-processamento, segmentação e análise.

A captura da imagem pode ser feita com o auxílio de câmera fotográfica e escâner, e é nesta etapa que ocorre a digitalização da imagem.

No pré-processamento haverá a melhoria da imagem, como o realce de contrastes e a remoção de ruídos, sendo esta etapa de grande importância para aumentar as chances de sucesso das etapas seguintes (GONZALEZ; WOODS, 2010).

A segmentação consiste nos processos de limiarização e reconhecimento dos objetos de interesse. A limiarização consiste na varredura da imagem original identificando os pixels pertencentes ao objeto e ao fundo, por meio de limiares ou limites pré-definidos, que podem ser por intensidade de cinza ou por variação de cor (GONZALEZ; WOODS, 2010). Para limiarização por cor pode-se utilizar vários tipos de modelo de cores na identificação dos pixels pertencentes ao objeto e ao fundo da imagem, entre eles estão os modelos de HSV, RGB CIELab e YCbCr descritos a seguir (LOPES, 2003): 
- Modelo HSV: composto por um sistema de cores formado pelos componentes de Matiz (Hue-H), Saturação (Saturation-S) e Valor (value-V). O matiz é responsável por verificar o tipo de cor que varia desde o vermelho até o violeta mais o magenta, em que a saturação regula a quantidade de tom de cinza que uma imagem apresentará, e o valor representa a intensidade de brilho;

- Modelo RGB: proposto por Young-Helmholtz; se baseia na teoria do estímulo de três cores: Vermelha (Red-R), Verde (Green-G) e Azul (Blue-B), que podem formar cores secundárias, como a cor magenta (vermelho mais azul), ciano (verde mais azul) e amarelo (vermelho mais verde);

- Modelo CIELab: definido pela Comission Internationale de I'Eclairage - CIE para aumentar a uniformidade das cores percebidas pelo sistema visual da pessoa. Funciona como um tradutor universal de línguas entre os dispositivos. Permitindo controlar as cores que passam de um dispositivo para outro e correlacionar os valores em RGB com os valores em "L" (a luminosidade que define a cor relativamente a ser mais clara ou mais escura nos limites do preto e branco), "a" (o tom que define a tonalidade da cor nos limites de verde e vermelho) e "b" (a saturação que define a intensidade ou pureza da cor nos limites de azul e amarelo);

- Modelo YCbCr: modelo desenvolvido para permitir que as emissões dos sistemas de televisores coloridos fossem compatíveis com os receptores preto e branco. É um sistema de espaços entre cores usado como parte do canal de cor de uma imagem, vídeo ou sistema de fotografia digital, no qual, "Y" representa o componente da luma, " $\mathrm{Cb}$ " a diferença de azul no componente chroma e $\mathrm{Cr}$ a diferença de vermelho no componente chroma (LOPES, 2003).

\subsubsection{Análise de imagens de plântulas}

Os primeiros estudos voltados para a aplicação de imagens digitais no ramo de sementes se iniciaram com o uso de softwares genéricos de processamento de imagens digitais com o objetivo de medir o comprimento de raízes de diversas espécies.

McCormac et al. (1990) discutiu a utilização de um sistema de avaliação automática de vigor a partir de imagens de plântulas de alface e obteve sucesso nos resultados, em que o sistema se mostrou tão eficiente quanto o método tradicional. Howarth e Stanwood (1993) desenvolveram um sistema de visão computacional com o objetivo de medir a taxa de 
crescimento de plântulas de alface e sorgo durante todo o período de germinação.

Cicero et al. (1998) utilizaram uma técnica combinada de obtenção de imagens por raios-X e processamento digital de imagens, para analisar os efeitos de danos mecânicos internos e externos em sementes de milho. Geralmente os algoritmos presentes em programas computacionais iniciam a leitura dos "pixels" de uma imagem pelo seu canto inferior esquerdo, até que encontram o primeiro "pixel” em conexão, ou seja, o primeiro "pixel” do primeiro objeto em análise; a esse "pixel" é atribuído o valor 1, como uma etiqueta, e aos outros "pixels" constituintes do objeto o valor 2. Assim, em leituras repetidas, outros objetos vão sendo mapeados com valores sucessivos, obtendo-se o reconhecimento da imagem (GONZALEZ; WOODS, 2010).

McDonald e Chen (1990) relataram que, além da utilização em agrometeorologia, a análise de imagens vem sendo adaptada para a análise de formas e dimensões de objetos contidos em uma cena. Alguns autores, como Vooren e Heijden (1993), valeram-se da análise de imagens digitais na agricultura para a determinação das dimensões de órgãos de uma planta.

O uso da análise de imagem em sistemas radiculares constitui exemplo de aplicação do método na agricultura (CRESTANA et al., 1994), como é o caso do sistema computacional SIARCS 3.0 , capaz de realizar medidas quantitativas, como o comprimento, e dinâmicas, como a topologia e a arquitetura em sistemas radiculares (JORGE et al., 1996).

Em 2001, pesquisadores da The Ohio State University nos Estados Unidos desenvolveram um sistema computacional de análise de imagens de plântulas, denominado Seed Vigor Imaging System-SVIS, que, por meio do processamento das imagens digitalizadas, calcula índices que se baseiam no crescimento e uniformidade inicial das plântulas. Este sistema foi utilizado inicialmente com plântulas de alface, porém tem demonstrado eficiência na avaliação do potencial fisiológico de sementes de outras espécies, como o milho (ALVARENGA et al., 2012; GOMES-JUNIOR et al., 2009; McDONALD, 2005; OTONI; McDONALD, 2005), soja (HOFFMASTER et al., 2003; MARCOS-FILHO; KIKUTI; LIMA, 2009), melão (MARCOS-FILHO et al., 2006), amendoim (MARCHI et al., 2011), pepino (CHIQUITO et al.,, 2012), trigo (SILVA; GOMES-JUNIOR; CICERO, 2012), crotalária (SILVA et al., 2012) e girassol (ROCHA, 2012).

Uma das vantagens da utilização do SVIS é o tempo para obtenção dos resultados, onde são utilizadas plântulas de apenas três dias de idade para gerar o índice de vigor, sendo menor do que o requerido para a realização do teste manualmente (HOFFMASTER et al., 
2003). De acordo com Gomes Junior et al. (2009), os resultados para uma amostra de 50 sementes podem ser obtidos em aproximadamente três minutos. Vale apena ressaltar outras vantagens desse sistema, que incluem a eliminação do erro humano, aumentando a confiabilidade dos dados para fins de comparação de diferentes lotes de sementes e a possibilidade de arquivamento das imagens para análise posterior (ALVARENGA et al., 2012).

Para a utilização do SVIS, inicialmente as imagens são capturadas com o auxílio de um escâner tendo como operador um software específico. Após esta etapa as imagens são analisadas pelo software SVIS, fornecendo os índices de vigor, uniformidade e crescimento, cujos valores podem variar de 1 a 1000. As fórmulas para o cálculo dos índices estão descritas abaixo (SAKO et al., 2001):

$$
\begin{aligned}
& \text { Índice de Vigor }=w_{\mathrm{C}} \text { crescimento }+w_{\mathrm{U}} \text { uniformidade, } \\
& \text { Índice de Crescimento }=\text { mín. }\left(w_{\mathrm{h}} * l_{\mathrm{h}}+w_{\mathrm{r}} * l_{\mathrm{r}}, 1000\right), \\
& \text { Índice de Uniformidade }=\text { máx. }\left(1000-\left(w_{\mathrm{sh}} * s_{\mathrm{h}}+w_{\mathrm{sr}} * s_{\mathrm{r}}+s_{\mathrm{total}}+w_{\mathrm{sr} / \mathrm{h}} * \mathrm{~s}_{\mathrm{r} / \mathrm{h}}\right)-\right. \\
& \left.w_{\mathrm{M}} * \mathrm{n}^{\mathrm{o}} \text { sementes mortas, } 0\right),
\end{aligned}
$$

Sendo,

- $l_{\mathrm{h}}$ e $l_{\mathrm{r}}$ : médias amostrais do comprimento do hipocótilo e da raiz;

- $s_{\mathrm{h}}, s_{\mathrm{r}}, s_{\text {total }}$ e $s_{\mathrm{r} / \mathrm{h}}$ : desvio padrão do comprimento do hipocótilo, da raiz, total e da razão da raiz pelo hipocótilo;

- w: o peso dos parâmetros.

Além de comparar diretamente o vigor dos lotes por meio da análise do crescimento de plântulas, os resultados obtidos pelo SVIS foram relacionados com os testes de envelhecimento acelerado para o milho doce (ALVARENGA et al., 2012), amendoim (MARCHI et al., 2011) e soja (MARCOS FILHO et al., 2009), e o teste e emergência em campo para o amendoim (MARCHI et al., 2011) e girassol (ROCHA, 2012). O SVIS também foi utilizado com sucesso na avaliação da eficiência do condicionamento osmótico em sementes de Guazuma ulmifolia L (BRANCALION et al., 2010) e de milho doce (GOMES JUNIOR et al., 2009). 
Em 2012, a empresa Tbit Tecnologia e Sistemas desenvolveu um sistema semelhante ao SVIS, denominado Sistema de Análise de Sementes - SAS, o qual possui diversas utilidades, dentre elas a avaliação da qualidade física e fisiológica de sementes. Nos anos posteriores o software passou por atualizações, em que, no ano de 2015, seu nome foi alterado para GroundEye.

O SAS, atual GroundEye, é composto por uma câmara de captação de imagem e um software de análise. A câmara é constituída de uma bandeja com fundo de acrílico transparente, no qual é disposto o objeto de análise, uma, ou duas câmeras fotográficas de alta resolução e, em seu interior, lâmpadas de LED para iluminação. O fundo da câmara de captação possui a coloração azul para um maior contraste com o objeto de interesse na imagem.

O GroundEye permite que a aquisição das imagens seja realizada de duas maneiras: realiza-se apenas a captura da imagem e depois a analisa, ou, captura-se e analisa-se a imagem ao mesmo tempo. A decisão de qual caminho escolher depende da existência de uma calibração pré-definida para o objeto a ser analisado.

Antes da captura e análise da imagem é necessário que o usuário do equipamento defina qual plano de fundo usar, ou seja, defina o padrão para a segmentação da imagem. A segmentação no GroundEye é realizada por diferença de cor, sendo que o software possui três opções de modelos de cor, o Cielab, HSV e YCbCr (Figura 1).

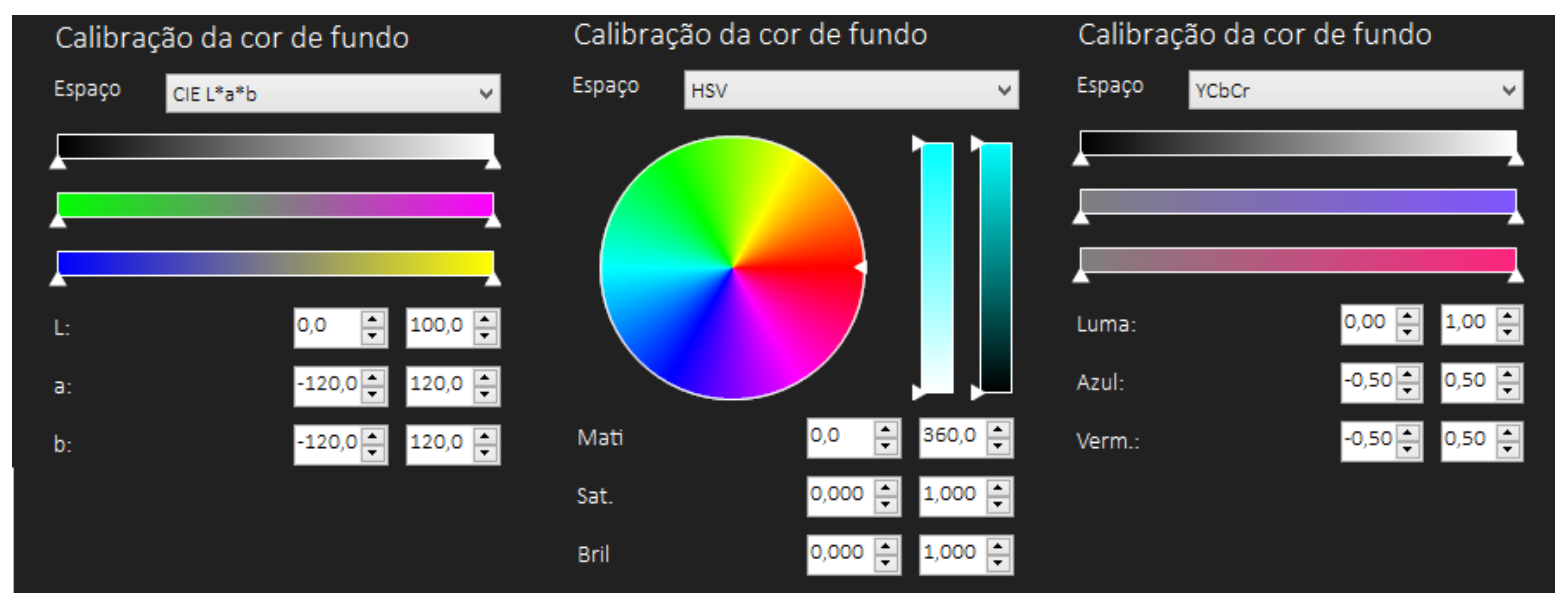

Figura 1 - Modelos Cielab, HSV e YCbCr para calibração da cor de fundo pelo software GroundEye, UnB, Brasília-DF, Brasil, 2017.

O GroundEye analisa imagens de sementes e de plântulas extraindo informações de cor, textura e geometria de cada indivíduo da imagem e a partir disso fornece informações 
sobre vigor, uniformidade e crescimento de cada amostra por meio dos índices, cujos valores variam de 1 a 100. A definição dos pesos de cada parâmetro dentro das fórmulas que o software utiliza para a obtenção do índice de crescimento, uniformidade e vigor é feita por meio de regressão multivariada. Tal processo é chamado de calibração automática e consiste na associação da imagem de plântulas de um determinado lote de sementes pelo software com o valor do teste de vigor (escolhido de acordo com a cultura utilizada) deste mesmo lote, para que desta forma o sistema complete o processo de aprendizado, ou seja, obtenha a calibração correta para a determinada cultura (PINTO, 2014). As fórmulas que o GroundEye utiliza para o cálculo desses índices são as mesmas do SVIS, porém todos os pesos dos parâmetros que compõem a fórmula podem ser modificados a cada análise.

Em trabalho realizado por Pinto et al. (2015) foram avaliados dois híbridos de milho, cada um representado por nove lotes, onde foi empregado o SAS (atual GroundEye) para avaliação de características de plântulas (comprimento médio do coleóptilo, da raiz e das plântulas) e pelos índices de vigor. A autora comparou o uso do SAS com calibração automática, obtida pelo SAS, e a calibração manual, onde os pesos utilizados foram os mesmos do SVIS, e verificou que a análise de imagem deve ser feita com a calibração automática pelo software SAS, sem necessidade de correção manual da imagem das plântulas (Figura 2). Concluiu também que o SAS é um equipamento promissor para a avaliação do potencial fisiológico de sementes de milho.

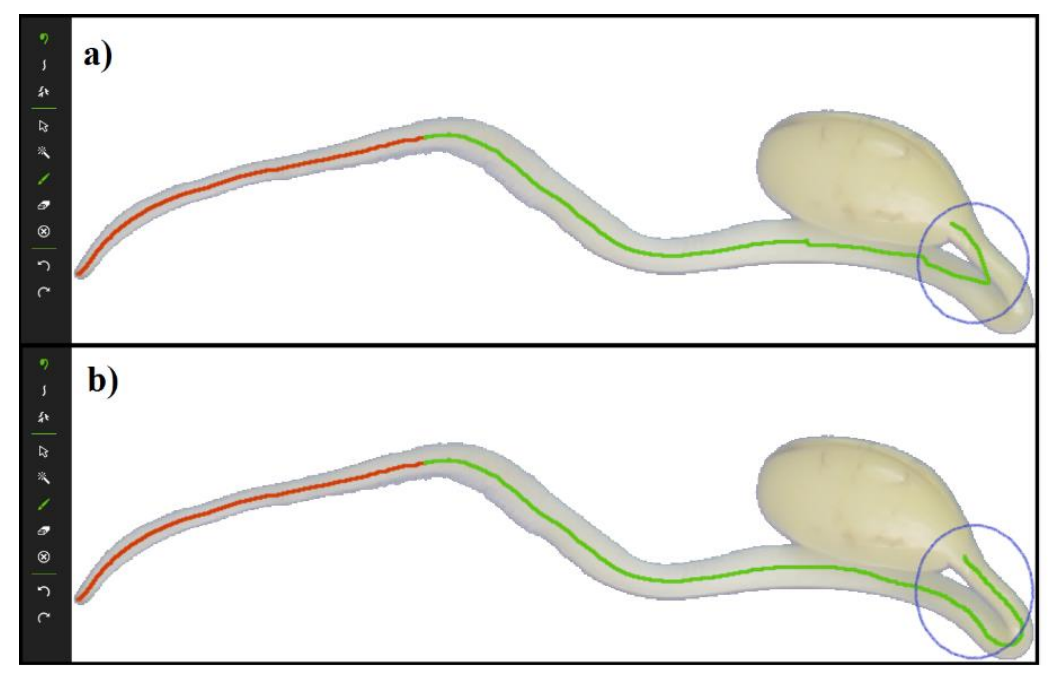

Figura 2 - Exemplo de correção da imagem das plântulas feito no software GroundEye: a) plântula sem correção e b) plântula com correção manual, UnB, Brasília-DF, Brasil, 2017 
O GroundEye é um equipamento com potencial de utilização para avaliação do vigor de sementes por meio da avaliação de imagens de plântulas, porém, é necessário realizar pesquisas para cada espécie, de maneira a comprovar a sua eficiência na avaliação do vigor de sementes.

Como na literatura não foi encontrado relato do uso do equipamento GroundEye com sementes de soja, o objetivo da pesquisa é adequar uma metodologia de análise de imagens de plântulas de soja pelo GroundEye, bem como verificar a potencialidade de utilização deste equipamento na avaliação do potencial fisiológico de sementes de soja. 


\section{MATERIAL E MÉTODOS}

Foram utilizados 16 lotes de sementes de soja com qualidade fisiológica distinta, sendo oito lotes da variedade 1 (98Y12) e oito lotes da variedade 2 (P98Y70), ambos fornecidos pela empresa DuPont ${ }^{\circledR}$ - Divisão Pioneer Sementes (Pioneer®).

Características da cultivar 98Y12:

- Cor do tegumento: amarelo.

- Cor da flor: branca.

- Cor da vagem: cinza escuro.

- Cor da pubescência: cinza.

- Cor do hilo: marrom clara.

- Cultivar com gene Roundup Ready® (tolerância ao herbicida Glifosato) e resistência ao Nematoide do Cisto da Soja (NCS).

Características da cultivar P98Y70:

- Cor do tegumento: amarelo.

- Cor da flor: branca.

- Cor da vagem: marrom clara.

- Cor da pubescência: marrom media.

- Cor do hilo: preto.

- Cultivar com gene Roundup Ready® (tolerância ao herbicida Glifosato).

\subsection{Análises laboratoriais e em campo}

A pesquisa foi realizada nos Laboratórios de Sementes da Empresa Pioneer® e da Faculdade de Agronomia e Medicina Veterinária do Campus Darcy Ribeiro - UnB. Os experimentos de campo foram realizados na Fazenda Água Limpa, da UnB, localizada na área rural da Vargem Bonita - DF.

Foram realizadas avaliações para caracterização da qualidade fisiológica dos lotes (germinação, teor de água, envelhecimento acelerado, teste de frio, tetrazólio, condutividade elétrica e emergência em campo) e também para a análise de imagens. 


\subsection{Caracterização dos lotes}

\subsubsection{Germinação}

Foram utilizadas quatro repetições de 50 sementes por tratamento, colocadas para germinar em substrato papel germitest na forma de rolo, umedecido com água destilada na quantidade equivalente a 2,5 vezes o peso do papel seco e colocadas em germinador regulado a $25^{\circ} \mathrm{C} \pm 2{ }^{\circ} \mathrm{C}$, segundo critérios descritos nas Regras para Análise de Sementes (BRASIL, 2009). Uma única leitura foi realizada ao quinto dia após a semeadura, onde foi computado o número de plântulas normais. Os resultados foram expressos em porcentagem.

\subsubsection{Teor de água}

Foi determinado o teor de água das sementes utilizadas pelo método de estufa a $105^{\circ} \mathrm{C}$ $\pm 2{ }^{\circ} \mathrm{C}$ por 24 horas (BRASIL, 2009) utilizando duas repetições de $5 \mathrm{~g}$ de sementes por tratamento. Os resultados foram expressos em porcentagem (base úmida).

\subsubsection{Envelhecimento acelerado}

O teste de envelhecimento acelerado foi conduzido em caixa plástica tipo gerbox $(11,0$ x 11,0 x 3,5 cm), pelo método de caixas plásticas de germinação (AOSA, 2009). As sementes de cada tratamento foram distribuídas sobre a tela inox interna em uma única camada, de maneira a cobri-la de forma completa e uniforme, e no fundo da caixa foi colocado $40 \mathrm{~mL}$ de água destilada. As caixas foram tampadas e mantidas em BOD regulada a $41^{\circ} \mathrm{C} \pm 2{ }^{\circ} \mathrm{C}$ durante 48 horas para posterior realização do teste de germinação segundo o item 4.2.1. Uma única leitura foi realizada ao sétimo dia após a semeadura computando a porcentagem de plântulas normais (MARCOS-FILHO, 1999). 


\subsubsection{Teste de frio}

Foram utilizadas quatro repetições de 50 sementes para cada tratamento. A semeadura foi realizada em bandejas de plástico $(51 / 30 / 9,7 \mathrm{~cm})$ utilizando uma mistura de solo e areia na proporção de 2:1, sendo umedecido com $60 \%$ da sua capacidade de retenção de água. Após a semeadura as caixas foram mantidas em câmara fria a $10^{\circ} \mathrm{C} \pm 2{ }^{\circ} \mathrm{C}$, durante cinco dias. Posteriormente as caixas foram acondicionadas em câmara de crescimento vegetal com temperatura de $25^{\circ} \mathrm{C} \pm 2{ }^{\circ} \mathrm{C}$ durante cinco dias, quando realizou-se a contagem de plântulas emergidas (BARROS et al., 1999). Os resultados foram expressos em porcentagem.

\subsubsection{Teste de tetrazólio}

Na condução do teste de tetrazólio, foram utilizadas 100 sementes (duas subamostras com 50 sementes) para cada variedade, tratamento e repetição, conforme indicaram França Neto et al. (1998). As amostras foram pré-condicionadas entre papel toalha umedecido, com quantidade de água equivalente a 2,5 vezes a massa do papel, durante $16 \mathrm{~h}$ e a $25^{\circ} \mathrm{C}$. Em seguida, as sementes foram colocadas em recipientes de plástico e mantidas submersas em solução $0,075 \%$ de cloreto de $2,3,5$ trifenil tetrazólio, a $40^{\circ} \mathrm{C}$ no escuro, por 150 minutos. Decorrido este período, as sementes foram lavadas em água corrente e analisadas de forma individual. Os resultados foram expressos em porcentagem de sementes viáveis e vigorosas.

\subsubsection{Condutividade elétrica}

Foram utilizadas duas repetições de 50 sementes para cada tratamento, previamente pesadas $(0,001)$, colocadas para embeber em copos plásticos $(200 \mathrm{~mL})$ contendo $75 \mathrm{~mL}$ de água deionizada e mantidas a $25^{\circ} \mathrm{C}$ por 24 horas. Decorrido o período de embebição, foi feita a leitura da condutividade elétrica, utilizando um condutivímetro DIGIMED, modelo CD 21, com eletrodo de constante 1.0, sendo os resultados finais expressos em $\mu \mathrm{S}^{-1} \mathrm{~cm}^{-1} \mathrm{~g}$ (NAKAGAWA, 1999). 


\subsubsection{Emergência de plântulas em campo}

O teste de emergência de plântulas em campo foi realizado na Fazenda Água Limpa, que pertence a UnB e localiza-se na área rural da Vargem Bonita - DF. A semeadura foi realizada manualmente, com quatro repetições de 50 sementes por tratamento, sendo as parcelas distribuídas ao acaso, espaçadas $10 \mathrm{~cm}$ entre linhas, a contagem das plântulas foi realizada após sete dias de instalação e o resultado expresso em percentual de número de plântulas normais emergidas (BRASIL, 2009).

\subsection{Análise de imagens}

Para a obtenção das imagens das plântulas foi realizado o teste de germinação utilizando-se quatro repetições de 50 sementes por tratamento, ou seja, por lote de cada variedade.

\subsubsection{Germinação}

Foi realizado o teste de germinação utilizando como substrato o papel toalha na forma de rolo umedecido com água equivalente a 2,5 vezes o seu peso seco. Posteriormente os rolos foram acondicionados em germinador regulado a $25{ }^{\circ} \mathrm{C} \pm 2{ }^{\circ} \mathrm{C}$ por três dias, quando foi realizada a captura das imagens.

\subsubsection{Comprimento de plântula e raiz.}

Após a captura das imagens das plântulas provenientes do teste de germinação ao terceiro dia, foi feita a medição manual das mesmas visando determinar o comprimento de plântula (CP) e de raiz (CR) (NAKAGAWA, 1994) para posterior comparação com o resultado obtido pelo software. Para efetuar as medições foi utilizada uma régua fixada na mesa por fita crepe (leitura em $\mathrm{cm}$ ). Para sementes mortas ou não germinadas deu-se valor zero. O resultado foi expresso em comprimento médio de plântula e de raiz, tanto pela medição manual quanto pelo software. 


\subsubsection{Captura de imagens}

Para a captura das imagens as plântulas foram retiradas do papel toalha de forma cuidadosa e foram colocadas sobre uma bandeja de acrílico transparente, de maneira que as plântulas não se encostassem. Posteriormente a bandeja foi inserida na câmara de captação do equipamento para captura das imagens e análise.

A captura das imagens do teste de germinação foi realizada por uma câmera profissional de alta resolução contida dentro da câmara de captação do equipamento GroundEye. Foram realizadas diversas tentativas até encontrar a melhor resolução.

\subsubsection{Calibração automática}

O processo de calibração automática realizado pelo software GroundEye (GE) consistiu na captura de imagens de plântulas de soja após três dias de semeadura provenientes do teste de germinação e posterior associação com o valor de vigor obtido pelo teste de envelhecimento acelerado para os mesmos lotes utilizados. Foram utilizados 38 lotes com aproximadamente 100 plântulas/lote para a captura das imagens, onde a variação de vigor foi de $44 \%$ a $97 \%$ pelo teste de envelhecimento acelerado. Estes lotes foram diferentes dos adotados para coleta de dados do trabalho, contudo todos da empresa Pioneer®.

Após este processo, o valor obtido pelo teste de envelhecimento acelerado foi associado pelo sistema à sua respectiva imagem para que, por meio de regressão multivariada, ocorresse a definição dos pesos dos parâmetros contidos nas fórmulas descritas abaixo:

- $\underline{\text { Índice de Crescimento }}=\operatorname{mín}\left(w_{\mathrm{h}} * l_{\mathrm{h}}+w_{\mathrm{r}} * l_{\mathrm{r}}, 1000\right)$,

- $\underline{\text { Índice de Uniformidade }}=\operatorname{máx}\left(1000-\left(w_{\mathrm{Sh}} * s_{\mathrm{h}}+w_{\mathrm{Sr}} * s_{\mathrm{r}}+s_{\mathrm{total}}+w_{\mathrm{Sr} / \mathrm{h}} * s_{\mathrm{r} / \mathrm{h}}\right)-W_{\mathrm{m}} * \mathrm{n}^{\mathrm{o}}\right.$ sementes mortas, 0 ),

- $\underline{\text { Índice de Vigor }}=p_{\mathrm{C}}$ crescimento $+p_{\mathrm{U}}$ uniformidade,

Sendo,

- $l_{\mathrm{h}}$ e $l_{\mathrm{r}}$ : médias amostrais do comprimento do hipocótilo e da raiz; 
- $S_{\mathrm{h}}, S_{\mathrm{r}}, S_{\text {total }}$ e $S_{\mathrm{r} / \mathrm{h}}$ : desvio padrão do comprimento do hipocótilo, da raiz, total e da razão da raiz pelo hipocótilo;

- $p_{\mathrm{C}}$ e $p_{\mathrm{U}}$ : peso dos índices de crescimento e uniformidade;

- w: o peso dos parâmetros.

\subsubsection{Reanálise de imagens}

Além da análise feita a partir da calibração automática do GroundEye, foi realizada a reanálise das imagens utilizando os mesmos pesos dos parâmetros do software SVIS, onde os valores dos pesos de crescimento e uniformidade foram de $70 \%$ e $30 \%$ respectivamente. $\mathrm{O}$ índice de vigor resultante da reanálise foi denominado Vigor SVIS (S).

\subsection{Delineamento experimental e análise estatística}

$\mathrm{O}$ experimento foi realizado em delineamento inteiramente casualizado com quatro repetições de 50 sementes para todos os testes utilizados (caracterização dos lotes e análise de imagens). Foram obtidas as análises de variância e as médias comparadas pelo teste de ScottKnott a 5\% de probabilidade Foi utilizado o software Assistat 7.7 (SILVA; AZEVEDO, 2009).

Para realizar a comparação dos testes de envelhecimento acelerado e comprimento de plântula e raiz com a análise de imagens foi realizada uma análise fatorial, sendo que os fatores considerados foram lotes e tipos de testes $(8 \times 2)$ para cada variedade. 


\section{RESULTADOS E DISCUSSÃO}

\subsection{Caracterização dos lotes}

Os valores obtidos na determinação do teor de água dos oito lotes das duas variedades de soja foram semelhantes, sendo que para os lotes da variedade 1 houve variação de 10,6\% a $11,9 \%$ e para os lotes da variedade 2 de $11,2 \%$ a 12,2\%. A uniformidade do teor de água entre lotes de sementes é de suma importância para a obtenção de resultados consistentes, pois diferenças maiores que 2 a 3 pontos percentuais podem interferir nos resultados dos testes de vigor (MARCOS FILHO, 1999), visto que a velocidade de absorção de água pelas sementes é uma característica de influência em tais testes.

Tabela 1. Resultados médios obtidos na avaliação qualidade fisiológica em sementes de soja de oito lotes da variedade 1, Brasília-DF, 2017.

\begin{tabular}{cccccccc}
\hline Lotes & $\mathrm{G}$ & $\mathrm{EC}$ & $\mathrm{EA}$ & $\mathrm{TF}$ & TZ Vig & TZ Viab & CE \\
\hline V1L1 & $93,00 \mathrm{a}$ & $94,00 \mathrm{a}$ & $92,00 \mathrm{a}$ & $92,50 \mathrm{a}$ & $93,00 \mathrm{a}$ & $95,00 \mathrm{a}$ & $110,52 \mathrm{~d}$ \\
V1L2 & $99,00 \mathrm{a}$ & $90,00 \mathrm{a}$ & $93,00 \mathrm{a}$ & $96,00 \mathrm{a}$ & $88,00 \mathrm{a}$ & $95,00 \mathrm{a}$ & $109,39 \mathrm{~d}$ \\
V1L3 & $85,00 \mathrm{~b}$ & $85,50 \mathrm{~b}$ & $82,00 \mathrm{~b}$ & $88,50 \mathrm{~b}$ & $72,00 \mathrm{~b}$ & $75,00 \mathrm{~b}$ & $144,73 \mathrm{c}$ \\
V1L4 & $81,50 \mathrm{~b}$ & $92,00 \mathrm{a}$ & $79,50 \mathrm{~b}$ & $88,00 \mathrm{~b}$ & $71,00 \mathrm{~b}$ & $75,00 \mathrm{~b}$ & $125,90 \mathrm{~d}$ \\
V1L5 & $97,50 \mathrm{a}$ & $91,50 \mathrm{a}$ & $96,00 \mathrm{a}$ & $92,50 \mathrm{a}$ & $91,00 \mathrm{a}$ & $93,00 \mathrm{a}$ & $173,06 \mathrm{~b}$ \\
V1L6 & $95,50 \mathrm{a}$ & $91,00 \mathrm{a}$ & $86,50 \mathrm{~b}$ & $95,00 \mathrm{a}$ & $92,00 \mathrm{a}$ & $95,00 \mathrm{a}$ & $111,95 \mathrm{~d}$ \\
V1L7 & $97,00 \mathrm{a}$ & $89,50 \mathrm{a}$ & $97,50 \mathrm{a}$ & $95,50 \mathrm{a}$ & $96,00 \mathrm{a}$ & $97,00 \mathrm{a}$ & $176,82 \mathrm{~b}$ \\
V1L8 & $84,00 \mathrm{~b}$ & $83,50 \mathrm{~b}$ & $76,00 \mathrm{~b}$ & $84,00 \mathrm{~b}$ & $84,00 \mathrm{a}$ & $87,00 \mathrm{a}$ & $211,58 \mathrm{a}$ \\
\hline CV & 4,33 & 4,17 & 7,57 & 6,08 & 6,86 & 3,89 & 5,39 \\
\hline
\end{tabular}

Médias seguidas de mesma letra minúscula nas colunas pertencem ao mesmo grupo, de acordo com o teste de Scott-Knott a 5\% de probabilidade; V1: variedade 1; L(n): lotes de 1 a 8; G: teste padrão de germinação; EC: emergência em campo; EA: envelhecimento acelerado; TF: teste de frio; TZ Vig: Tetrazólio vigor; TZ Viab: Tetrazólio viabilidade; CE: condutividade elétrica.

Na Tabela 1 constam os resultados da caracterização dos oito lotes da variedade 1. Pode-se verificar que todos os lotes apresentaram valores acima de $80 \%$ no teste de germinação, sendo este o padrão mínimo para comercialização de sementes de soja no Brasil (BRASIL, 2013). No entanto, pelo teste de germinação os lotes 1, 2, 5, 6 e 7 foram os que apresentaram os maiores valores e os lotes 3,4 e 8 os menores.

Para o teste de emergência de plântulas em campo a diferença entre os lotes foi mínima, onde apenas os lotes 3 e 8 se diferenciaram estatísticamente dos demais, obtendo os menores valores de germinação em campo. Pela proximidade entre os resultados de emergência em campo e germinação, é possível inferir que tais lotes, além de possuírem vigor 
alto, não encontraram condições de campo adversas, o que os possibilitou expressar todo seu potencial.

A partir do teste de envelhecimento acelerado observa-se o potencial de vigor dos lotes utilizados no experimento, possibilitando a classificação dos lotes em dois níveis, onde os maiores valores obtidos foram os dos lotes $1,2,5$ e 7 e os menores para os lotes $3,4,6$ e 8 . Tal resultado condiz com o alto nível de germinação em condições de laboratório e em campo, observado para os lotes 1, 2, 5, 6 e 7 .

Conforme destacado por Hampton e Coolbear (1990), um único teste de vigor não é capaz de caracterizar todas as possíveis interações entre as sementes e as condições ambientais variadas que enfrentam em campo quando são semeadas. Sendo assim, foram utilizados um conjunto de testes de vigor para caracterizar os lotes desse trabalho.

Os resultados do vigor dos lotes dessa variedade pelos testes de envelhecimento acelerado, teste de frio e tetrazólio foram superiores a $80 \%$, com exceção dos lotes 4 e 8 no teste de envelhecimento acelerado e os lotes 3 e 4 no tetrazólio. Ou seja, os testes de vigor adotados no estudo, foram eficientes na classificação de lotes da variedade 1 (Tabela 1).

Os resultados do teste tetrazólio (TZViab e TZVig) e do teste de frio corroboram com a conclusão de que os lotes 1, 2, 5, 6 e 7 foram os lotes que obtiveram melhor resultado, apesar de não se diferenciarem estatísticamente do lote 8 no teste de tetrazólio. Tais resultados comprovam o alto desempenho de tais lotes em uma ampla gama de condições ambientais.

De acordo com França Neto et al. (1998), no teste de tetrazólio, valores acima de 85\% são para lotes com vigor muito alto; entre $84 \%$ e $75 \%$ vigor alto; entre 74 e $60 \%$ vigor médio; entre $59 \%$ e $50 \%$, vigor baixo e inferior a isso vigor muito baixo. Nesse contexto, os lotes 1 , 2, 5, 6 e 7 são lotes que apresentaram vigor muito alto; o lote 8 com vigor alto e os demais com vigor médio.

Pelo teste de condutividade elétrica, os lotes com os melhores resultados, ou seja, com menor valor, foram os lotes 1, 2, 4 e 6. Já o maior valor foi encontrado no lote 8, demonstrando não só por este teste, mas também pelos testes de germinação, emergência em campo, envelhecimento acelerado e teste de frio, ser o lote com os piores resultados referentes à sua qualidade fisiológica.

No teste de condutividade elétrica, quanto menor o resultado melhor é a qualidade, uma vez que nesse teste, quanto maior o valor da condutividade, maior a quantidade de lixiviados liberados para a solução de embebição, e assim, pior é a qualidade da semente (VIEIRA; CARVALHO, 1994). Valores entre 60-70 $\mu \mathrm{S}^{-1} \mathrm{~cm}^{-1} \mathrm{~g}$ são tidos como sementes de 
alto vigor, enquanto $70-80 \mu \mathrm{S}^{-1} \mathrm{~cm}^{-1} \mathrm{~g}$ já são valores com tendência para médio vigor (VIEIRA; CARVALHO, 1994). Nos EUA, considera-se que, condutividade de sementes de soja superior a $150 \mu \mathrm{S}^{-1} \mathrm{~cm}^{-1} \mathrm{~g}$, é um indicativo de sementes de baixo vigor (AOSA, 1983).

Nesse estudo, os valores de condutividade estão todos acima de $80 \mu \mathrm{S}^{-1} \mathrm{~cm}^{-1} \mathrm{~g}$, sendo que os lotes 5, 7 e 8 apresentaram valores acima de 150 e estariam de acordo com o teste de condutividade elétrica considerado como baixo vigor. Daí a importância da análise de mais de um teste de vigor.

Considerando todos os testes, os lotes com os menores valores referentes à qualidade fisiológica são os lotes 3, 4 e 8, sendo os lotes onde se observou a maior variação entre os resultados. Esta variação é mais visível justamente em lotes de potencial fisiológico intermediário e baixo, visto que o processo de deterioração de um lote de sementes afeta cada semente individualmente, fazendo com que esta variação seja mais visível (PINTO, 2014). De acordo com Illipronti-Junior (1997), para espécies como a soja, os lotes de maior vigor, são também os que apresentam maior homogeneidade.

Tabela 2. Resultados médios obtidos na avaliação qualidade fisiológica em sementes de soja de oito lotes da variedade 2, Brasília-DF, 2017.

\begin{tabular}{cccccccc}
\hline Lotes & $\mathrm{G}$ & $\mathrm{EC}$ & $\mathrm{EA}$ & $\mathrm{TF}$ & TZ Vig & TZ Viab & CE \\
\hline V2L1 & $87,00 \mathrm{~b}$ & $70,00 \mathrm{~b}$ & $76,00 \mathrm{~b}$ & $83,00 \mathrm{~b}$ & $84,00 \mathrm{~b}$ & $84,00 \mathrm{c}$ & $206,57 \mathrm{a}$ \\
V2L2 & $85,00 \mathrm{~b}$ & $71,50 \mathrm{~b}$ & $73,00 \mathrm{~b}$ & $81,00 \mathrm{~b}$ & $67,00 \mathrm{~d}$ & $71,00 \mathrm{~d}$ & $205,76 \mathrm{a}$ \\
V2L3 & $87,00 \mathrm{~b}$ & $67,50 \mathrm{~b}$ & $84,00 \mathrm{a}$ & $87,00 \mathrm{a}$ & $78,00 \mathrm{c}$ & $83,00 \mathrm{c}$ & $208,18 \mathrm{a}$ \\
V2L4 & $97,50 \mathrm{a}$ & $77,00 \mathrm{a}$ & $92,00 \mathrm{a}$ & $91,00 \mathrm{a}$ & $97,00 \mathrm{a}$ & $99,00 \mathrm{a}$ & $207,48 \mathrm{a}$ \\
V2L5 & $88,00 \mathrm{~b}$ & $70,00 \mathrm{~b}$ & $79,00 \mathrm{~b}$ & $84,00 \mathrm{~b}$ & $77,00 \mathrm{c}$ & $80,00 \mathrm{c}$ & $206,59 \mathrm{a}$ \\
V2L6 & $80,00 \mathrm{~b}$ & $78,50 \mathrm{a}$ & $78,00 \mathrm{~b}$ & $84,50 \mathrm{~b}$ & $85,00 \mathrm{~b}$ & $86,00 \mathrm{c}$ & $206,35 \mathrm{a}$ \\
V2L7 & $94,00 \mathrm{a}$ & $79,00 \mathrm{a}$ & $90,00 \mathrm{a}$ & $93,00 \mathrm{a}$ & $90,00 \mathrm{~b}$ & $91,50 \mathrm{~b}$ & $226,04 \mathrm{a}$ \\
V2L8 & $84,50 \mathrm{~b}$ & $76,50 \mathrm{a}$ & $86,50 \mathrm{a}$ & $84,50 \mathrm{~b}$ & $84,00 \mathrm{~b}$ & $86,00 \mathrm{c}$ & $262,71 \mathrm{a}$ \\
\hline CV & 5,01 & 5,16 & 7,66 & 5,67 & 4,83 & 4,58 & 8,92 \\
\hline
\end{tabular}

Médias seguidas de mesma letra minúscula nas colunas pertencem ao mesmo grupo, de acordo com o teste de Scott-Knott a 5\% de probabilidade; V2: variedade 1; L(n): lotes de 1 a 8 ; G: teste padrão de germinação; EC: emergência em campo; EA: envelhecimento acelerado; TF: teste de frio; TZ Vig: Tetrazólio vigor; TZ Viab: Tetrazólio viabilidade; CE: condutividade elétrica.

$\mathrm{Na}$ caracterização dos oito lotes da variedade 2, descrita na tabela 2, pode-se verificar uma maior variação entre os resultados de qualidade fisiológica. Pelo teste de germinação podemos verificar que todos os lotes apresentaram valores acima de $80 \%$. Ainda sobre este teste, da mesma forma que na variedade 1, é possível classificar os 8 lotes da variedade $2 \mathrm{em}$ 
dois níveis, onde os melhores resultados foram observados nos lotes 4 e 7 . Tal resultado é semelhante ao do teste de emergência de plântulas em campo, sendo os lotes 4, 6, 7 e 8 os que obtiveram os melhores resultados, porém tal teste obteve uma taxa de germinação muito inferior, onde todos os lotes ficaram com média a baixo de $80 \%$. Possivelmente este resultado refletiu numa maior sensibilidade das sementes da variedade 2 às condições de campo, demonstrando um menor desempenho de emergência em campo se comparado com a variedade 1. Além disto, no geral as médias dos testes de vigor da variedade 2 também foram menores e variaram mais, sendo esta a possível causa de tal resultado no teste de emergência em campo. De acordo com Matthews \& Powell (1986, apud SCHUAB, 2002), a baixa taxa de emergência em campo não está frequentemente associada às falhas na germinação, mas sim ao processo de crescimento pré e pós-emergência, sendo tal fator influenciado pelas condições do solo e pelo vigor das sementes utilizadas.

No teste de envelhecimento acelerado pode-se observar uma maior diferença de vigor entre os lotes, possibilitando a classificação dos mesmos em dois níveis, em que os lotes 3, 4, 7 e 8 foram os que obtiveram o melhor resultado. Neste teste os lotes 1, 2, 5 e 6 apresentaram média abaixo de $80 \%$, sendo classificados como de vigor médio/baixo.

Para o teste de frio observa-se que os lotes 3, 4 e 7 foram os que obtiveram o melhor índice de vigor. Já no teste de tetrazólio observou-se uma grande variação entre os resultados, tanto para o índice de vigor quanto para a viabilidade, possibilitando a classificação dos mesmos em quatro níveis de vigor, em que o lote 4 obteve o melhor resultado.

Apesar da grande variação encontrada nos resultados dos testes de caracterização da qualidade fisiológica dos lotes da variedade 2, pode-se observar que os lotes que demostraram melhor desempenho geral foram o 4 e 7 , tanto pela análise estatística quanto pela verificação do valor numérico presente nos resultados de cada um dos testes, demonstrando a superioridade de tais lotes no que se refere à sua qualidade fisiológica.

O teste de condutividade elétrica não demonstrou diferença estatística, no entanto os resultados demonstram um nível muito alto de condutividade elétrica, o que demonstra um nível deterioração alto para todos os lotes. Tal resultado, apesar de não entrar em concordância com os demais testes de vigor utilizados, pode ser justificado pela grande variação encontrada nos resultados dos testes de caracterização da qualidade fisiolígica dos lotes da variedade 2, sendo evidenciado principalmente no teste de emergência de plântulas em campo que demonstrou uma maior sensibilidade quando comparado com os lotes da variedade 1. 
Por meio da caracterização da qualidade fisiológica dos lotes das variedades de soja utilizadas pode-se identificar: (a) para a variedade 1, os lotes 1, 2, 5, 6 e 7 foram classificados como de alto vigor em todos os testes utilizados na caracterização, com exceção do teste de envelhecimento acelerado e condutividade elétrica e os lotes 3,4 e 8 foram classificados como de vigor médio e; (b) para a variedade 2, os lotes 4 e 7 foram classificados como de alto vigor na maioria dos testes utilizados na caracterização, com exceção do teste de condutividade elétrica para os lotes 4 e 7 e tetrazólio para o lote 7, os lotes $1,3,5,6$ e 8 tendem à classificação de médio vigor e o lote 2 tende a ser classificado como de vigor baixo.

\subsection{Análise de imagens}

Com relação à captura de imagens os melhores ajustes encontrados para definição de imagens estão descritos a seguir.

A calibração de cor de fundo utilizado foi o espaço de cor HSV com matiz entre 198,4 e 278,4, saturação entre 0,389 e 1,000 e brilho de 0,000 a 1,000 (Figura 3). O tipo de parâmetro de reconhecimento foi plântulas com três dias, fundo de preenchimento não selecionado e o tamanho mínimo de descarte de objeto de $0,3 \mathrm{~cm}^{2}$.

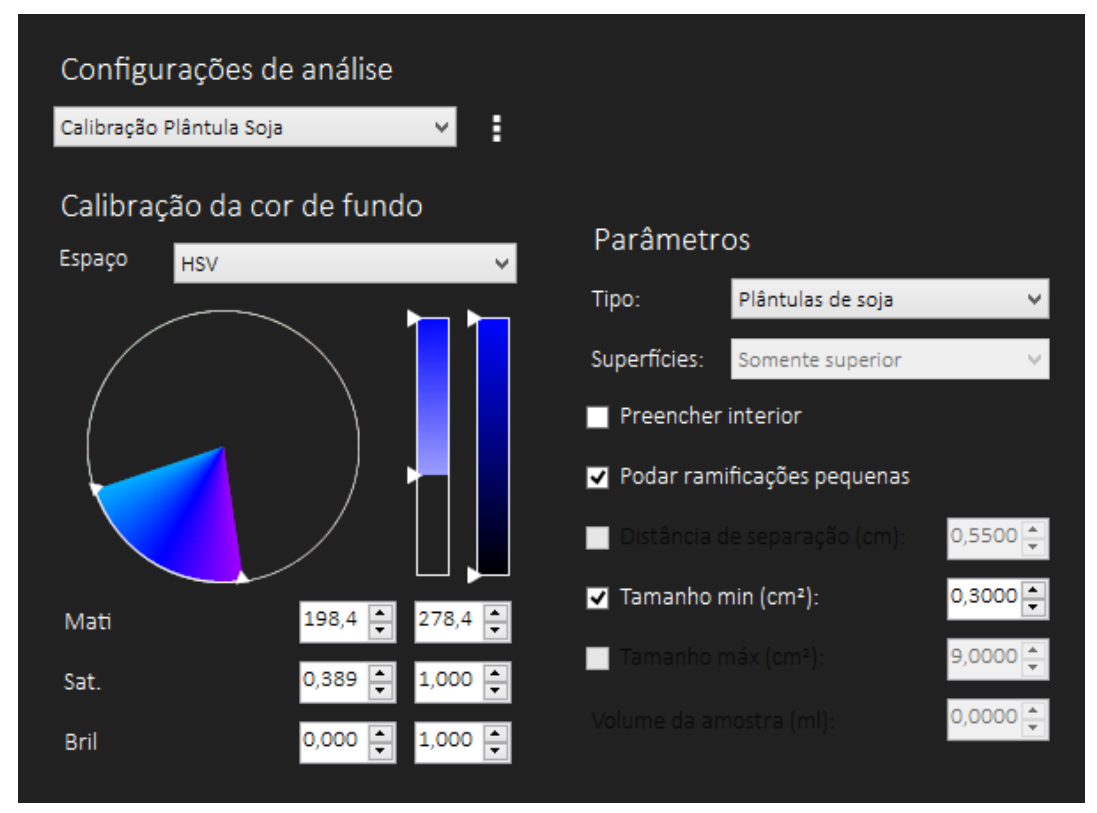

Figura 3 - Configuração de análise utilizada na análise de imagens de plântulas de soja pelo software GroundEye, UnB, Brasília-DF, Brasil, 2017. 
As plântulas analisadas pelo software GroundEye no presente trabalho não passaram por correção manual das partes das plântulas (coleóptilo e raiz), visto que a detecção automática foi eficiente. Isto representa um avanço no uso do equipamento, visto que se tem um ganho de tempo e mão de obra, já que a leitura é feita de forma imediata.

$\mathrm{Na}$ tabela 3 consta a média dos resultados dos testes obtidos de forma manual [envelhecimento acelerado (EA) e comprimento de plântula $(\mathrm{CP})$ e raiz $(\mathrm{CR})$ ] e pelo software GroundEye [Vigor Automático (VA) e comprimento de plântula (GE CP) e raiz (GECR)] para oito lotes de sementes da variedade 1 .

Vanzolini et al (2007) buscou correlacionar os dados de comprimento de plântula e raiz com os dados de emergência de plântulas em campo e concluiu que somente o comprimento de raiz obteve tal correlação de forma a diferenciar os lotes de soja. Assim como Vanzolini et al (2007), outros autores também relataram ser o comprimento de raiz mais sensível na diferenciação de lotes de sementes de soja (KRZYANOWSKI 1991; NAKAGAWA, 1999; VANZOLINI; 2002).

Pelo resultado do teste de envelhecimento acelerado, apresentado na tabela 3 foi possível classificar os lotes em dois grupos, onde os maiores valores encontrados foram dos lotes 1, 2, 5 e 7. Já o resultado do índice de vigor automático indicou também o lote 6 como mais vigoroso, sendo este resultado idêntico ao verificado na caracterização dos lotes (ítem 5.1) onde os lotes 1, 2, 5, 6 e 7 foram caracterizados como de alto vigor.

Tabela 3. Valores médios obtidos nos testes de envelhecimento acelerado (EA), Vigor Automático (VA), comprimento de plântula e raiz via medição manual (CP e CR) e comprimento de plântula e raiz via GroundEye (GE CP e GE CR) para oito lotes da variedade 1, UnB, Brasília - DF, 2017.

\begin{tabular}{ccc|cccc}
\hline Lotes & EA & VA & CP & GE CP & CR & GE CR \\
\hline V1L1 & $92,00 \mathrm{aA}$ & $90,50 \mathrm{aA}$ & $7,03 \mathrm{bA}$ & $6,86 \mathrm{bA}$ & $4,63 \mathrm{bA}$ & $3,84 \mathrm{bA}$ \\
V1L2 & $93,00 \mathrm{aA}$ & $96,00 \mathrm{aA}$ & $8,87 \mathrm{aA}$ & $8,93 \mathrm{aA}$ & $5,92 \mathrm{aA}$ & $5,05 \mathrm{aA}$ \\
V1L3 & $82,00 \mathrm{bA}$ & $79,00 \mathrm{bA}$ & $6,62 \mathrm{bA}$ & $6,74 \mathrm{bA}$ & $4,27 \mathrm{bA}$ & $4,13 \mathrm{bA}$ \\
V1L4 & $79,50 \mathrm{bA}$ & $76,00 \mathrm{bA}$ & $7,45 \mathrm{bA}$ & $7,07 \mathrm{bA}$ & $4,46 \mathrm{bA}$ & $4,13 \mathrm{bA}$ \\
V1L5 & $96,00 \mathrm{aA}$ & $97,00 \mathrm{aA}$ & $9,61 \mathrm{aA}$ & $9,01 \mathrm{aA}$ & $6,19 \mathrm{aA}$ & $5,44 \mathrm{aA}$ \\
V1L6 & $86,50 \mathrm{bA}$ & $92,50 \mathrm{aA}$ & $9,32 \mathrm{aA}$ & $9,36 \mathrm{aA}$ & $5,92 \mathrm{aA}$ & $5,27 \mathrm{aA}$ \\
V1L7 & $97,50 \mathrm{aA}$ & $94,50 \mathrm{aA}$ & $7,21 \mathrm{bA}$ & $7,01 \mathrm{bA}$ & $4,99 \mathrm{bA}$ & $4,07 \mathrm{bA}$ \\
V1L8 & $76,00 \mathrm{bA}$ & $74,50 \mathrm{bA}$ & $7,01 \mathrm{bA}$ & $6,37 \mathrm{bA}$ & $4,63 \mathrm{bA}$ & $3,78 \mathrm{bA}$ \\
\hline CV & 7,57 & 6,69 & 6,91 & 10,91 & 7,76 & 14,57 \\
\hline
\end{tabular}

Médias seguidas de mesma letra minúscula nas colunas e maiúscula nas linhas pertencem ao mesmo grupo, de acordo com o teste de Scott-Knott a 5\% de probabilidade. 
Comparando os resultados do envelhecimento acelerado com os valores de VA do software, observa-se que não existe diferença entre as duas formas de avaliar o vigor dos lotes, ou seja, a avaliação realizada pelo software pode ser comparada estatisticamente com os dados do teste de envelhecimento acelerado (tabela 3).

Os resultados do comprimento de plântula e raiz, tanto via medição manual quanto via software GroundEye, indicam os lotes 2, 5 e 6 como os lotes mais vigorosos.

Com relação à comparação entre a análise realizada pelo software para comprimento de plântula (GE CP) e raiz (GE CR) e a medição manual de $\mathrm{CP}$ e CR, observa-se que não existe diferença estatística entre os dois tipos de análise para todos os lotes. Isto demonstra a eficiência da análise realizada pelo software GroundEye.

Tabela 4. Valores médios dos índices de Crescimento (C), Uniformidade (U) e Vigor SVIS (S) obtidos pelo software GroundEye para oito lotes da variedade 1, UnB, Brasília - DF, 2017.

\begin{tabular}{cccc}
\hline Lotes & $\mathrm{C}$ & $\mathrm{U}$ & $\mathrm{S}$ \\
\hline V1L1 & $26,28 \mathrm{~b}$ & $91,24 \mathrm{a}$ & $45,77 \mathrm{~b}$ \\
V1L2 & $34,96 \mathrm{a}$ & $89,62 \mathrm{a}$ & $51,36 \mathrm{a}$ \\
V1L3 & $26,26 \mathrm{~b}$ & $88,40 \mathrm{~b}$ & $44,91 \mathrm{~b}$ \\
V1L4 & $27,43 \mathrm{~b}$ & $87,84 \mathrm{~b}$ & $45,55 \mathrm{~b}$ \\
V1L5 & $35,67 \mathrm{a}$ & $90,33 \mathrm{a}$ & $52,07 \mathrm{a}$ \\
V1L6 & $36,38 \mathrm{a}$ & $87,96 \mathrm{~b}$ & $51,86 \mathrm{a}$ \\
V1L7 & $27,44 \mathrm{~b}$ & $91,08 \mathrm{a}$ & $46,53 \mathrm{~b}$ \\
V1L8 & $24,64 \mathrm{~b}$ & $87,71 \mathrm{~b}$ & $43,56 \mathrm{~b}$ \\
\hline CV & 11,93 & 3,17 & 5,73 \\
\hline
\end{tabular}

Médias seguidas de mesma letra minúscula nas colunas pertencem ao mesmo grupo, de acordo com o teste de Scott-Knott a 5\% de probabilidade.

Pelos resultados do índice de crescimento e vigor SVIS foi possível classificar os lotes da variedade 1 em dois grupos, onde os lotes 2, 5 e 6 foram superiores. Tal classificação é a mesma que a verificada no comprimento de plântula e raiz via medição manual e via software GroundEye (Tabela 3). Já o índice de uniformidade indicou os lotes 1, 2, 5 e 7 como os de melhor resultados, sendo a mesma classificação obtida no teste de envelhecimento acelerado (Tabela 3).

Silva e Cicero (2014) concluíram que o comprimento de plântulas e os índices de vigor e de crescimento obtidos na análise via SVIS são eficientes na classificação de lotes de sementes de berinjela. No trabalho de Pinto et al (2015), apenas o índice de uniformidade não 
obteve resultados satisfatórios para a classificação da qualidade fisiológica de sementes de milho.

$\mathrm{Na}$ tabela 5 consta a média dos resultados dos testes obtidos de forma manual [envelhecimento acelerado (EA) e comprimento de plântula (CP) e raiz (CR)] e pelo software GroundEye [Vigor Automático (VA) e comprimento de plântula (GE CP) e raiz (GECR)] para oito lotes de sementes da variedade 2 .

O resultado do índice de vigor automático indica os lotes 4,7 e 8 como os mais vigorosos (tabela 5). O mesmo resultado foi visto para o comprimento de plântula e raiz via software GroundEye e comprimento de raiz via medição manual. Tais resultados foram diferentes do resultado do teste de envelhecimento acelerado, pois o mesmo também classificou o lote 3 como mais vigoroso. Pela medição manual do comprimento de plântula observamos que os lotes 4, 5, 6, 7 e 8 obtiveram os melhores resultados.

Tabela 5. Valores médios obtidos nos testes de envelhecimento acelerado (EA), Vigor automático (VA), comprimento de plântula e raiz via medição manual (CP e CR) e comprimento de plântula e raiz via GroundEye (GE CP e GE CR) para oito lotes da variedade 2, UnB, Brasília - DF, 2017.

\begin{tabular}{ccc|cc|cc}
\hline Lotes & EA & VA & CP & GE CP & CR & GE CR \\
\hline V2L1 & $76,00 \mathrm{bA}$ & $73,00 \mathrm{bA}$ & $6,54 \mathrm{bA}$ & $6,10 \mathrm{bA}$ & $4,50 \mathrm{cA}$ & $3,69 \mathrm{bA}$ \\
V2L2 & $73,00 \mathrm{bA}$ & $72,00 \mathrm{bA}$ & $6,74 \mathrm{bA}$ & $6,60 \mathrm{bA}$ & $4,32 \mathrm{cA}$ & $3,70 \mathrm{bA}$ \\
V2L3 & $84,00 \mathrm{aA}$ & $81,00 \mathrm{bA}$ & $7,25 \mathrm{bA}$ & $6,86 \mathrm{bA}$ & $5,02 \mathrm{bA}$ & $3,85 \mathrm{bA}$ \\
V2L4 & $92,00 \mathrm{aA}$ & $94,00 \mathrm{aA}$ & $8,28 \mathrm{aA}$ & $7,70 \mathrm{aA}$ & $5,52 \mathrm{aA}$ & $4,53 \mathrm{aA}$ \\
V2L5 & $79,00 \mathrm{bA}$ & $77,00 \mathrm{bA}$ & $8,02 \mathrm{aA}$ & $6,88 \mathrm{bA}$ & $5,26 \mathrm{bA}$ & $3,96 \mathrm{bA}$ \\
V2L6 & $78,00 \mathrm{bA}$ & $80,00 \mathrm{bA}$ & $7,99 \mathrm{aA}$ & $6,87 \mathrm{bA}$ & $5,04 \mathrm{bA}$ & $3,95 \mathrm{bA}$ \\
V2L7 & $90,00 \mathrm{aA}$ & $94,00 \mathrm{aA}$ & $8,23 \mathrm{aA}$ & $8,04 \mathrm{aA}$ & $5,78 \mathrm{aA}$ & $4,66 \mathrm{aA}$ \\
V2L8 & $86,50 \mathrm{aA}$ & $92,00 \mathrm{aA}$ & $8,04 \mathrm{aA}$ & $7,86 \mathrm{aA}$ & $5,64 \mathrm{aA}$ & $4,68 \mathrm{aA}$ \\
\hline CV & 7,66 & 7,78 & 6,72 & 15,36 & 7,67 & 18,34 \\
\hline
\end{tabular}

Médias seguidas de mesma letra minúscula nas colunas e letra maiúscula nas linhas pertencem ao mesmo grupo, de acordo com o teste de Scott-Knott a 5\% de probabilidade.

Apesar de uma maior variação entre os resultados dos lotes da variedade 2 , todos os testes obtiveram os lotes 4 e 7 entre os melhores resultados, confirmando a superioridade dos mesmos assim como o descrito na caracterização dos lotes da variedade 2. Tal variação contribuiu de forma positiva para a avaliação da eficiência do GroundEye, visto que sua eficiência foi observada mesmo em lotes com vigor mediano/baixo. 
Além da comparação entre os lotes, foi feita a comparação entre o tipo de teste (manual e pelo software), em que não se verificou diferença estatística tanto no envelhecimento acelerado quanto para o comprimento de plântula e raiz, em todos os lotes da variedade 2. Estes resultados ressaltam a eficiência do software GroundEye na avaliação do vigor de sementes de soja, uma vez que os seus resultados podem ser estatisticamente comparados com as análises realizadas manualmente.

Marcos Filho (2009), ao utilizar o software SVIS para obtenção do índice de vigor em sementes de soja, não obteve resultados sensíveis o bastante para verificar a diferença de vigor entre os lotes. Este resultado foi justificado devido a grande recorrência de índices de vigor alto nos lotes utilizados por ele, ocasionando tal insensibilidade. Já Sekharan (2005), também utilizando o SVIS, constatou a eficiência das análises para verificar diferenças no potencial fisiológico de sementes de soja envelhecidas artificialmente, variando entre $83 \%$ e 95\% de germinação.

Tabela 6. Valores médios dos índices de Crescimento (C), Uniformidade (U) e Vigor SVIS (S) obtidos pelo software GroundEye para oito lotes da variedade 2, UnB, Brasília - DF, 2017.

\begin{tabular}{cccc}
\hline Lotes & $\mathrm{C}$ & $\mathrm{U}$ & $\mathrm{S}$ \\
\hline V2L1 & $23,41 \mathrm{~b}$ & $88,30 \mathrm{a}$ & $42,87 \mathrm{~b}$ \\
V2L2 & $25,76 \mathrm{~b}$ & $89,84 \mathrm{a}$ & $44,98 \mathrm{~b}$ \\
V2L3 & $26,77 \mathrm{~b}$ & $88,82 \mathrm{a}$ & $45,39 \mathrm{~b}$ \\
V2L4 & $30,16 \mathrm{a}$ & $90,54 \mathrm{a}$ & $48,28 \mathrm{a}$ \\
V2L5 & $26,56 \mathrm{~b}$ & $89,29 \mathrm{a}$ & $45,38 \mathrm{~b}$ \\
V2L6 & $24,68 \mathrm{~b}$ & $87,50 \mathrm{a}$ & $46,07 \mathrm{~b}$ \\
V2L7 & $31,63 \mathrm{a}$ & $90,11 \mathrm{a}$ & $49,15 \mathrm{a}$ \\
V2L8 & $31,27 \mathrm{a}$ & $89,00 \mathrm{a}$ & $48,59 \mathrm{a}$ \\
\hline CV & 16,93 & 2,08 & 5,6 \\
\hline
\end{tabular}

Médias seguidas de mesma letra minúscula nas colunas pertencem ao mesmo grupo, de acordo com o teste de Scott-Knott a 5\% de probabilidade.

Na tabela 6 constam os resultados médios dos índices de crescimento, unifomidade e vigor SVIS para os oito lotes da variedade 2. O resultado dos índices de vigor manual e de crescimento possibilitaram a classificação dos lotes em dois níveis, sendo os lotes 4,7 e 8 os de maior vigor. Tal resultado é o mesmo encontrado para o índice de vigor automático, comprimento de plântula e raiz via software GroundEye e comprimento de raiz via medição manual (tabela 5). Já o índice de uniformidade obteve resultados muito próximos, não obtendo diferença estatística. 
As informações referentes aos índices de crescimento e uniformidade, assim como o comprimento de plântula e raiz, obtidos pelo software GroundEye, apesar de não terem apresentado sensibilidade para a classificação dos lotes das duas variedades estudadas, ainda assim influenciaram de forma positiva a classificação dos lotes pelo índice de vigor automático, visto que são fatores que o compõem, comprovando desta forma, a eficiência do equipamento na avaliação do vigor de plântulas de soja.

Uma comparação entre a avaliação realizada de forma manual e pelo GroundEye, seja pelo teste de envelhecimento acelerado quanto pelo comprimento de plântula e raiz demonstra a eficiência do equipamento GroundEye na avaliação da qualidade fisiológica quanto ao vigor de sementes de soja.

Outro ponto importante a se considerar, é que os resultados do vigor automático e comprimento de plântula e raiz via equipamento GroundEye foram obtidos a partir de plântulas com apenas três dias após semeadura. A avaliação do vigor de plântulas de soja, com menos dias que o normalmente preconizado pelas Regras para Análise de Sementes (BRASIL, 2009) seria uma grande contribuição para os programas de controle de qualidade das empresas produtoras de sementes, visto que é constante a necessidade de informações rápidas quanto a qualidade da semente durante o processo de produção.

As informações desse estudo oferecem uma oportunidade de utilização dessa ferramenta em programas de controle de qualidade de empresas produtoras de semente de soja. 


\section{CONCLUSÃO}

A avaliação de vigor realizada pelo envelhecimento acelerado e o índice de vigor do GroundEye foi igual na comparação dos lotes de soja.

Os resutados da medição manual do comprimento de plântula e raiz com a medição do GroundEye são compatíveis.

A avaliação do vigor de sementes de soja por meio da análise de imagem via software GroundEye pode ser realizada em plântulas obtidas em semeadura em papel de germinação, a temperatura de $25^{\circ} \mathrm{C}$ com avaliação ao terceiro dia, sem necessidade de correção da imagem das plântulas.

O GroundEye demonstrou ser um equipamento promissor na a avaliação do vigor de sementes de soja, podendo ser adotado como teste complementar no controle de qualidade de empresas produtoras de sementes. 


\section{REFERÊNCIAS BIBLIOGRÁFICAS}

ALVARENGA, R. O.; MARCOS-FILHO, J.; GOMES-JUNIOR, F. G. Avaliação do vigor de sementes de milho super doce por meio da análise computadorizada de imagens de plântulas. Revista Brasileira de Sementes, Londrina, v. 34, n. 3, p. 488-494, set. 2012.

AOSA - Association of Official Seed Analysts. Seed vigor testing handbook. East Lasing, AOSA. 88p. 1983.

AOSA - ASSOCIATION OF OFFICIAL SEED ANALYSTS. Seed vigor testing handbook. Lincoln, 2009. 105 p. (Contribution, 32).

BAALBAKI, R. et al. Seed vigor testing handbook. Lincoln: AOSA, 2009. 346 p. (Contribution, 32).

BARROS, A. S. R. et al. Teste de frio. In: KRZYZANOWSKI, F. C.; VIEIRA, R. D.; FRANÇA-NETO, J. B. (Ed.). Vigor de sementes: conceitos e testes. Londrina: ABRATES, 1999. cap. 5, p. $1-5$.

BARTSCH, J.A.; HAUGH, C.G.; ATHOW, K.L.; PEART, R.M. Impact damage to soybean seed. Transactions of the ASAE, St. Joseph, v. 29, n. 2, p. 582-586, 1986.

BINO, R.J.; AARTSE, J.W.; VAN DER BURG, W.J. Nondestructive X-ray analysis of Arabidopsis embryo mutants. Seed Science Research, v.3, n.3, p.167-170, 1993.

BITTENCOURT, S. R. M. et al. Metodologia alternativa para condução do teste de envelhecimento acelerado em sementes de milho. Ciência Rural, Santa Maria, v. 42, n. 8, p. 1360-1365, ago. 2012.

BITTENCOURT, S. R. M.; VIEIRA, R. D. Temperatura e período de exposição de sementes de milho no teste de envelhecimento acelerado. Revista Brasileira de Sementes, Londrina, v. 28, n. 3, p. 161-168, set. 2006.

BRANCALION, P. H. S. et al. Priming of pioneer tree Guazuma ulmifolia (Malvaceae) seeds evaluated by an automated computer image analysis. Scientia Agricola, Piracicaba, v. 67, n. 3, p. 274-279, 2010.

BRASIL. Ministério da Agricultura, Pecuária e Abastecimento. Instrução Normativa, $\mathrm{N}^{\circ} 45$, de 17 de setembro de 2013. Diário Oficial da União, DF, 20 set. 2013. p. 25, Seção 1. 
BRASIL. Ministério da Agricultura, Pecuária e Abastecimento. Regras para análise de sementes. Brasília: SNDA/DNDV/CLAV, 2009. 399 p.

CARVAlHO, M. A. C.; LAZARINI, E.; EUSTÁQUiO DE SÁ, M.; OLIVEIRA, A. L. Variações na metodologia do teste de frio para avaliação do vigor em sementes de soja. Revista Brasileira de Sementes, Jaboticabal, vol. 22, n. 1, p. 74-80, 2000.

CHIQUITO, A. A.; GOMES-JUNIOR, F. G.; MARCOS-FILHO, J. Assessment of physiological potential of cucumber seeds using the software Seedling Vigor Imaging System (SVIS). Revista Brasileira de Sementes, Londrina, v. 34, n. 2, p. 255-263, jun. 2012.

CÍCERO, S.M.; VAN DER HEIJDEN, G.W.A.M.; VAN DER BURG, W.J.; BINO, R.J. Evaluation of mechanical damage in seeds of maize (Zea mays L.) by X-ray and digital imaging. Seed Science and Technology, Zürich, v.26, n.3, p.603-612, 1998.

CÍCERO, S.M.; VIEIRA, R.D. Teste de frio. In: VIEIRA, R.D.; CARVALHO, N.M. (Eds.). Testes de vigor em sementes. Jaboticabal: FUNEP, 1994. p.151-164.

CONAB - COMPANHIA NACIONAL DE ABASTECIMENTO. Acompanhamento da Safra Brasileira - Grãos, v. 4 - Safra 2016/17 - Quarto levantamento, Jan. 2017. Disponível em: < http://www.conab 2015.pdf >. Acesso em: 10 Jan. 2017.

COSTA, N. P.; MARCOS FILHO, J. Temperatura e pré-condicionamento de sementes de soja para o teste de tetrazólio. Scientia Agricola, Piracicaba, v. 51, n. 1, p. 158-168, 1994.

CRESTANA, S.; GUIMARÃES, M.F.; JORGE，L.A.C.; RALISCH，R.; TOZZI，C.L.; TORRE, A. \& VAZ, C.M. Avaliação da distribuição de raízes no solo auxiliada por processamento de imagens digitais. Revista Brasileira de Ciência do Solo, Campinas, v.18, n.3, p.365-372, 1994.

DAN, E.L.; MELLO, V.D.C.; WETZEL, C.T.; POPINIGIS, F.; ZONTA, E.P. Transferência de matéria seca como modo de avaliação do vigor de sementes de soja. Revista Brasileira de Sementes, Brasília, v. 9, n.3, p. 45-55, 1987.

DELOUCHE, J.C.; STILL, T.W.; KASPET, M.; LIENHARD, M. O teste de tetrazólio para viabilidade da semente. Brasília: AGIPLAN, 1976. 103p.

DESWAL, D.P.; SHEORAN, I.S. A simple method for seed leakage measurement: applicable to single seeds of any size. Seed Science and Technology, v.21, p.179-185, 1993. 
DIAS, D. C. F. S.; MARCOS-FILHO, J. Testes de vigor baseados na permeabilidade das membranas celulares. I. Condutividade elétrica. Informativo Abrates, Londrina, v. 5, n. 1, p. 26-36, 1995.

DORNELAS, M. C.; LOBO, C. A.; VIEIRA, I. G. Avaliação do tamanho de plântulas de Eucalyptus spp. após a germinação, comutilização de análise de imagens digitais auxiliada por computador. Scientia Forestalis, Piracicaba, n. 68, p. 125-130, 2005.

DUTRA, A. S.; VIEIRA, R. D. Envelhecimento acelerado como teste de vigor para sementes de milho e soja. Ciência Rural, Santa Maria, v. 34, n. 3, p. 715-721, jun. 2004.

FRANÇA NETO, J.B.; PEREIRA, L.A.G.; COSTA, N.P.; KRZYZANOWSKI, F.C.; HENNING, A.A. Metodologia do teste de tetrazólio em sementes de soja. Londrina: EMBRAPA-CNPSo, 1988. 60p. (Documentos, 37).

FRANÇA-NETO, J.B.; KRZYZANOWSKI, F.C.; COSTA, N.P. da. O teste de tetrazólio em sementes de soja. Londrina: EMBRAPA-CNPSo, 1998. 72p. (EMBRAPA-CNPSo. Documentos, 116).

GAZZONI, D. L. Efeito de populações de percevejos na produtividade, qualidade da semente e características agronômicas da soja. Pesquisa Agropecuária Brasileira, Brasília, v.33, n.8, p.1229-1237, ago. 1998.

GIURIZATTO, M.I.K.; SOUZA, L.C.F.; ROBAINA, A.D.; GONÇALVES, M.C. Efeito da época de colheita e da espessura do tegumento sobre a viabilidade e o vigor de sementes de soja. Ciência e Agrotecnologia, Lavras, v. 27, n. 4, p. 771-779, 2003.

GOMES JUNIOR, F. G. et al. Evaluation of priming effects on sweet corn seeds by SVIS. Seed Technology, Lincoln, v. 31, n. 6, p. 95-100, 2009.

GONZALEZ, R. C.; WOODS, R. E. Digital image processing. 3 ed. New Jersey: PrendiceHall, 2010. 976 p.

GUNASEKARAN, S.; COOPER, T.M.; BERLAGE, A.G. Evaluating quality factors of corn and soybeans using a computer vision system. Transactions of the ASAE, v.31, n.4, p.12641271, 1988.

HAMPTON, J.G.; COOLBEAR, P. Potential versus actual seed performance. Can vigour testing provide an answer? Seed Science and Technology. v. 18, n.2, p. 215-228, 1990. 
HOFFMASTER, A. L. et al. An automated system for vigor testing three-day old soybean seedlings. Seed Science and Technology, v. 31, n. 3, p. 701-713, 2003.

HOWARTH, M. S.; SATANWOOD, P. C. Measurement of seedling growth rate by machine vision. Transactions of American Society of Agricultural Engineering, Saint Joseph, v. 36, n. 3, p. 959-963, 1993.

ILLIPRONTI JUNIOR, R. A. Variation in quality of individual seeds within a seed lot of soybean [Glycine $\max$ (L.) Merrill]. 1997. 157 p. Thesis (Ph.D. in Landbouw) Wageningen University, Wageningen, 1997.

ISELY, D. Vigor Tests. Proceedings of the Association of Seed Analysts 47, p.176-182, 1957.

ISTA - INTERNATIONAL SEED TESTING ASSOCIATION. International rules for testing seed. Seed Science and Technology, v.13, n.2, p.300-520, 1995.

JORGE, L.A.C.; RALISCH, R.; ABI SAAB, O.J.G.; MEDINA, C.C.; GUIMARÃES, M.F.; NEVES, C.S.V.J.; CRESTANA, S.; CINTRA, F.L.D.; BASOI, L.H.; FERNANDES, S.B.V. Aquisição de imagens de raízes. In: JORGE, L.A.C. (Ed.). Recomendações práticas para aquisição de imagens digitais analisadas através do SIARCS. São Carlos : EmbrapaCNPDIA, 1996. 48p. (Embrapa-CNPDIA. Circular Técnica, 1). CD-ROM.

JUNIOR, F. G. G. Aplicação da análise de imagens para avaliação da morfologia interna de sementes. Informativo ABRATES, vol. 20, nº.3, p. 33-39, 2010.

KAPPES, C.; CARVALHO, M.A.C.; YAMASHITA,O.M. Potencial fisiológico de sementes de soja dessecadas com Diquat e Paraquat. Scientia Agraria, Curitiba, v. 10, n. 1, p. 1-6, 2009.

KRZYANOWSKI, F.C.; FRANÇA-NETO, J.B.; HENNING, A.A.; COSTA, N.P. A Semente de soja como tecnologia e base para altas produtividades - Série Sementes. Circular técnica 55. Londrina, PR, abril de 2008.

LEOPOLD, A.C. Temperature effects on soybean imbibition and leakage. Plant Physiology, v.65, p.1096-1098, 1980.

LOEFFLER, T.M.; TEKRONY, D.M.; EGLI, D.B. The bulk conductivity test as in indicator of soybean seed quality. Journal of Seed Technology, v.12, p.37-53, 1988. 
LOPES, J. M. B. Computação gráfica: cor e luz. Lisboa: Universidade Técnica de Lisboa 2003. 45 p.

MARCHI, J. L.; CÍCERO, S. M.; GOMES-JUNIOR, F. G. Utilização da análise computadorizada de plântulas na avaliação do potencial fisiológico de sementes de amendoim tratadas com fungicida e inseticida. Revista Brasileira de Sementes, Londrina, v. 33, n. 4, p. 652-662, dez. 2011.

MARCOS FILHO, J. Seed vigor testing: an overview of the past, present and future perspective. Scientia Agricola, Piracicaba, vol.72 n.4 p.363-374. July/Aug. 2015.

MARCOS FILHO, J. Teste de Envelhecimento Acelerado. In.: KRYZANOWSKI, F.C.; VIEIRA, R.D.; FRANÇA NETO, J. DE B. (Ed.) Vigor de sementes: conceitos e testes. Londrina: ABRATES, 1999, p.3.1-3.24.

MARCOS FILHO, J.; KIKUTI, A. L. P.; LIMA, L. B. Métodos para avaliação do vigor de sementes de soja, incluindo a análise computadorizada de imagens. Revista Brasileira de Sementes, Londrina, v. 31, n. 1, p. 102-112, jan./fev. 2009.

MARCOS-FILHO, J. et al. Assessment of melon seed vigour by an automated computer imaging system compared to traditional procedures. Seed Science and Technology, Zurich, v.34, n. 2, p. 485-497, July 2006.

McCORMAC, Q. C.; KEFFE, P. D.; DRAPER, R. S. Automated vigour testing of field vegetables using image analysis. Seed Science and Technology, Zurich, v. 18, n. 1, p. 103112,1990

McDONALD, M. B. A review and evaluation of seed vigor tests. Proceedings of Association of Official Seed Analysts 65, p. 109-139, 1975.

MCDONALD, M. B. The Ohio State University Seed Vigor Imaging System (SVIS) for soybean and corn seedlings. Seed Science and Technology, Zurich, v. 27, n. 1, p. 7-24, Feb. 2005.

McDONALD, T.; CHEN, Y. R. Application of morphological image processing in agriculture. American Society of Agricultural and Biological Engineers, Saint Joseph, v. 33, n. 4, p. 1346-1352, 1990.

MENEGHELlO, G. E.; PESKE, S. T. A grandeza do negócio de sementes de soja no Brasil. Revista SEEDNews, reportagem da capa, jul/ago 2013 - Ano XVII - N. 4. Disponível em: < 
http://seednews.inf.br/_html/site/content/reportagem_capa/index.php?edicao=81> Acesso em: 23 de outubro de 2016.

MIGUEL, M.H.; CÍCERO, S.M. Teste de frio na avaliação do vigor de sementes de soja. Revista Brasileira de Sementes, v. 21, n 2, p.35-42, 1999.

NAKAGAWA, J. Testes de vigor baseados na avaliação de plântulas. In: KRZYZANOWSKI, F.C.; VIEIRA, R.D.; FRANÇA-NETO, J.B. (Eds.). Vigor de sementes: conceitos e testes. Londrina: ABRATES, 1999. p.2:1- 2:21.

NAKAGAWA, J. Testes de vigor baseados na avaliação das plântulas. In: VIEIRA, R. D., CARVALHO, N. M. (Ed.) Testes de vigor em sementes. Jaboticabal: FUNEP, 1994. p.4985.

NAKAGAWA, J. Testes de vigor baseados no desempenho das plântulas. In: KRZYZANOSKI, F.C.; VIEIRA, R.D.; FRANÇA NETO, J.B. (Ed.). Vigor de sementes: conceitos e testes. Londrina: ABRATES, 1999. p.2.1-2.24.

NERY, M. C.; CARVALHO, M. L. M.; GUIMARÃES, R. M. Testes de vigor para avaliação da qualidade de sementes de nabo forrageiro. Informativo ABRATES, Londrina, v. 19, n. 1, p. 9-20, 2009.

OBANDO FLOR, E.P.; CÍCERO, S.M.; FRANÇA-NETO, J.B.; KRZYZANOWSKI, F.C. Avaliação de danos mecânicos em sementes de soja por meio da análise de imagens. Revista Brasileira de Sementes, Brasília, v. 26, n. 1, p. 68-76, 2004.

OHLSON, O. C. et al. Teste de envelhecimento acelerado de trigo. Revista Brasileira de Sementes, Londrina, v. 32, n. 4, p. 118-124, 2010.

OTONI, R. R.; McDONALD, M. B. Moisture and temperature effects on maize and soybean seedlings using the seed vigor imaging system. Seed Science and Technology, Zurich, v. 27, n. 2, p. 243-247, July 2005.

PANOBIANCO, M.; VIEIRA, R.D. Electrical conductivity of soybean soaked seeds. I. Effect of genotype. Pesquisa Agropecuária Brasileira, v.31, p.621-627, 1996.

PANOBIANCO, M.; VIEIRA, R.D.; KRZYZANOWSKI, F.C.; FRANÇA-NETO, J.B. Electrical conductivity of soybean seed and correlation with seed coat lignin content. Seed Science and Technology, v.27, p.945-949, 1999. 
PINTO, C. A. G. Image analysis in the evaluation of the physiological potential of maize seeds. Revista de Ciência Agronômica, Fortaleza, v. 46, n. 2, p 319-328, abr-jun, 2015.

PINTO, C.A.G. Análise de imagens na avaliação do potencial fisiológico em sementes de milho. Lavras: UFLA, 2014. 52p. (Mestrado - UFLA).

PINTO, T.L.F. Avaliação de danos causados por percevejos, de danos mecânicos e de deterioração por umidade, em sementes de soja, utilizando a técnica de analise de imagens. 2006. Piracicaba: USP, 2006. 57 p. (Mestrado - USP).

POWELL, A.A. Cell membranes and seed leachate conductivity in relation to the quality of seed for sowing. Journal of Seed Technology, v.10, p.81-100, 1986.

ROCHA, C. R. M. Avaliação da qualidade de sementes de girassol por meio de análise de imagens. Piracicaba: USP, 2012. 68 p. (Mestrado - USP).

SAKO, Y. et al. A system for automated seed vigour assessment. Seed Science and Technology, Zurich, v. 29, n. 3, p. 625-636, 2001.

SCHMIDT, D.H.; TRACY, W.F. Duration of imbibition affects seed leachate conductivity in sweet corn. HortScience, v.24, p.346-347, 1989.

SCHUAB, S. R. P.; BRACCINI, A. L.; FRANÇA-NETO, J. B.; SCAPIM, C. A.; MESCHEDE, D. K. Utilização da taxa de crescimento das plântulas na avaliação do vigor de sementes de soja. Revista Brasileira de Sementes, v. 24, n. 2, p. 90-95, 2002.

SCHUAB, S. R. P.; BRACCINI, A. L.; FRANÇA-NETO, J. B.; SCAPIM, C. A.; MESCHEDE, D. K. Utilização da taxa de crescimento das plântulas na avaliação do vigor de sementes de soja. Revista Brasileira de Sementes, v. 24, n. 2, p. 90-95, 2002.

SEAB - SECRETARIA DE ESTADO DA AGRICULTURA E DO ABRASTECIMENTO. DEPARTAMENTO DE ECONOMIA RURAL. Soja - Análise da conjuntura agropecuária.; Novembro, 2013. Disponível em: <http://www.agricultura.pr.gov.br/arquivos/File/deral/Prognosticos/soja_2013_14.pdf> Acesso em: 21 de novembro de 2016.

SEKHARAN, S. Aged soybean seeds - their physiology and vigor assessment. 2006. $180 \mathrm{f}$. Tese (Ph.D) - The Ohio State University, Columbus/OH/EUA, 2005.

SHORT, G.E.; LACY, M.L. Carbohydrate exudation from pea seeds: Effect of cultivar, seed age, seed color, and temperature. Phytopathlogy, v.66, p.182-187, 1976. 
SILVA, C. B. et al. Automated system of seedling image analysis (SVIS) and electrical conductivity to assess sun hemp seed vigor. Revista Brasileira de Sementes, Londrina, v. 34, n. 1, p. 55-60, mar. 2012.

SILVA, F.A.S.; AZEVEDO, C.A.V. Principal components analysis in the software assistatstatistical assistance. In: 7th World Congress on Computers in Agriculture, 2009, Reno. Proceedings of the 7th World Congress on Computers in Agriculture. St. Joseph: ASABE, 2009. v. CD-Rom. p.1-5.

SILVA, V. N.; GOMES JUNIOR, F. G.; CICERO, S. M. Computerized maging analysis of seedlings for assessment of physiological potential of wheat seeds. Revista Brasileira de Sementes, Londrina, v. 34, n. 4, p. 589-596, 2012.

SIMACK, M.; GUSTAFSSON, A. X-ray photography and sensitivity in forest tree species Hereditas. 39 p.458-468, 1953.

SOUZA, S. A.; NAKAGAWA, J.; MACHADO, C. G. Teste deenvelhecimento acelerado em sementes de aveia preta. Revista Brasileira de Sementes, Londrina, v. 31, n. 2, p. 155-163, 2009.

STYER, R.C.; CANTLIFFE, D.J.O. Changes in seed structure and composition during development and their effects on leakage in two endosperm mutants of sweet corn. Journal of American Society of Horticultural Science, v.108, p.721- 728, 1983.

TAO, J.K. Factors causing variations in the conductivity test for soybean seeds. Journal of Seed Technology, v.3, p.10-18, 1978.

THRONEBERRY, G.O.; SMITH, F.G. Relation of respiratory and enzimatic activity to corn seed viabity. Plant Physiology, Bethesda, v.30, n.4, p.337-343, 1955.

USDA - UNITED STATES DEPARTMENT OF AGRICULTURE. World Agricultural Production. Disponível em: <http://apps.fas.usda.gov/psdonline/circulars/production.pdf〉. Acesso em: 13 de Janeiro de 2017.

VANZOLINI, S.; CARVALHO, N. M. Efeito do vigor de sementes de soja sobre o seu desempenho em campo. Revista Brasileira de Sementes, Londrina, v. 24, n. 1, p. 33-41, 2002. 
VANZOLINI, S.;ARAKI, C.A.S.; SILVA, A.C.M.T.; NAKAGAWA, J. Teste de comprimento de plântula na avaliação da qualidade fisiológica de sementes de soja. Revista Brasileira de Sementes, v. 29, n. 2, p. 90-96, 2007.

VERNETTI, F. de J.; VERNETTI JÚNIOR, F. de J. V. Genética da soja: caracteres qualitativos e diversidade genética. Brasília, DF: Embrapa Informação Tecnológica, 2009.

VIEIRA, R. D. Teste de condutividade elétrica. In: VIEIRA, R. D.; CARVALHO, N. M. Testes de vigor em sementes. Jaboticabal: FUNEP, 1994. p. 103-139.

VIEIRA, R. D.; BITTENCOURT, S. R. M.; PANOBIANCO, M. Seed vigour: an important component of seed quality in Brazil. ISTA - Seed Testing International, Zürich, v. 126, n. 1, p. 21-22, 2003.

VIEIRA, R. D.; CARVALHO, N. M. Testes de vigor em sementes. Jaboticabal: Funep, 1994.

VIEIRA, R. D.; KRZYZANOWSKI, F. C. Teste de condutividade elétrica. In: KRZYZANOWSKI, F. C.; VIEIRA, R. D.; FRANÇA NETO, J. B. (Ed.). Vigor de sementes: conceitos e testes. Londrina: ABRATES, 1999. p. 4.1-4.26.

VIEIRA, R. D.; PENARIOL, A. L.; PERECIN, D.; PANOBIANCO, M. Condutividade elétrica e teor de água inicial das sementes de soja. Pesquisa Agropecuária Brasileira, Brasília, v. 37, n. 9, p. 1333-1338, set. 2002.

VOOREN, J.G.; HEIJDEN, G.W.A.M. Measuring the size of french beans with image analysis. Plant Varieties and Seeds, v.6, n.47, p.47-53, 1993.

WRASSE, C. F. et al. Testes de vigor para sementes de arroz e sua relação com o comportamento de hidratação de sementes e a emergência de plântulas. Científica, Jaboticabal, v. 37, n. 2, p. 107-114, 2009. 


\section{ANEXOS}

\section{ANEXO A - Análise de variância dos testes de qualidade fisiológica de sementes de soja}

de oito lotes das variedades 1 e 2, Brasília-DF, 2017.

Anexo A1. Análise de variância dos testes de qualidade fisiológica de sementes de soja de oito lotes da variedade 1, Brasília-DF, 2017.

QM

\begin{tabular}{lccccccc}
\hline \multicolumn{1}{c}{ FV } & G & EC & EA & TF & TZ Vig & TZ Viab & CE \\
\hline Tratamento & $193,83^{* *}$ & $48,50^{*}$ & $256,83^{* *}$ & $73,14 \mathrm{~ns}$ & $182,53^{*}$ & $166,85^{* *}$ & $2898,67^{* *}$ \\
Resíduo & 15,7 & 14 & 44,2 & 31 & 34,75 & 12 & 61,52 \\
\hline CV & 4,33 & 4,17 & 7,57 & 6,08 & 6,86 & 3,89 & 5,39 \\
\hline MG & 91,56 & 89,62 & 87,81 & 91,5 & 85,87 & 89 & 145,49 \\
\hline
\end{tabular}

** Significativo a 1\% de probabilidade pelo teste F; * Significativo a 5\% de probabilidade pelo teste F; ns Não significativo pelo teste F; QM: Quadrado médio; FV: Fator de variação; CV: Coeficiente de variação; MG: Média geral; G: teste padrão de germinação; EC: emergência em campo; EA: envelhecimento acelerado; TF: teste de frio; TZ Vig: Tetrazólio vigor; TZ Viab: Tetrazólio viabilidade; CE: condutividade elétrica

Anexo A2. Análise de variância dos testes de qualidade fisiológica de sementes de soja de oito lotes da variedade 2, Brasília-DF, 2017.

\begin{tabular}{lccccccc}
\multicolumn{1}{c}{ FV } & TPG & EC & EA & TF & TZ Vig & TZ Viab & CE \\
\hline Tratamento & $121,92^{* *}$ & $80,28^{* *}$ & $188,26^{* *}$ & $67,14^{*}$ & $324,28^{* *}$ & $266,41^{* *}$ & $797,63 \mathrm{~ns}$ \\
Resíduo & 19,41 & 14,5 & 39,79 & 23,75 & 16 & 15,2 & 372,11 \\
\hline CV & 5,01 & 5,16 & 7,66 & 5,67 & 4,83 & 4,58 & 8,92 \\
MG & 87,87 & 73,75 & 82,31 & 86 & 82,75 & 85,06 & 216,21 \\
\hline
\end{tabular}

** Significativo a $1 \%$ de probabilidade pelo teste F; * Significativo a $5 \%$ de probabilidade pelo teste F; ns Não significativo pelo teste F; QM: Quadrado médio; FV: Fator de variação; CV: Coeficiente de variação; MG: Média geral; G: teste padrão de germinação; EC: emergência em campo; EA: envelhecimento acelerado; TF: teste de frio; TZ Vig: Tetrazólio vigor; TZ Viab: Tetrazólio viabilidade; CE: condutividade elétrica 


\section{ANEXOB - Análise de variância dos testes de análise de imagens de sementes de soja de oito lotes das variedades 1 e 2, Brasília-DF, 2017.}

Anexo B1. Análise de variância dos testes de análise de imagens de sementes de soja de oito lotes da variedade 1, Brasília-DF, 2017.

QM

\begin{tabular}{lcccccccc}
\hline \multicolumn{1}{c}{ FV } & VA & C & U & VM & CP & GE CP & CR & GE CR \\
\hline Tratamento & $351,75^{* *}$ & $190,95^{* *}$ & $17,51^{*}$ & $96,42^{* *}$ & $5,58^{* *}$ & $11,69^{* *}$ & $2,33^{* *}$ & $3,64^{* *}$ \\
Resíduo & 34,3 & 12,72 & 8,02 & 7,48 & 0,29 & 0,7 & 0,15 & 0,42 \\
\hline CV & 6,69 & 11,93 & 3,17 & 5,73 & 6,91 & 10,91 & 7,76 & 14,57 \\
MG & 87,55 & 29,88 & 89,27 & 47,7 & 7,89 & 7,67 & 5,12 & 4,46 \\
\hline
\end{tabular}

** Significativo a $1 \%$ de probabilidade pelo teste F; * Significativo a 5\% de probabilidade pelo teste F; ns Não significativo pelo teste F; QM: Quadrado médio; FV: Fator de variação; CV: Coeficiente de variação; MG: Média geral; VA: vigor automático; C: índice de crescimento; U: índice de uniformidade; VM: vigor manual; CP: comprimento de plântula por medição manual; GE CP: comprimento de plântula via GroundEye; CR: comprimento de raiz por medição manual; GE CR: comprimento de raiz via GroundEye.

Anexo B2. Análise de variância dos testes de análise de imagens de sementes de soja de oito lotes da variedade 2, Brasília-DF, 2017.

$\mathrm{QM}$

\begin{tabular}{lcccccccc}
\hline \multicolumn{1}{c}{ FV } & VA & C & U & VM & CP & GE CP & CR & GE CR \\
\hline Tratamento & $338,14 * *$ & $77,13 * *$ & $7,92 *$ & $37,08^{*}$ & $1,92^{* *}$ & $3,69 * *$ & $1,10^{* *}$ & $1,45^{*}$ \\
Resíduo & 41,63 & 21,73 & 3,44 & 12,66 & 0,26 & 1,19 & 0,15 & 0,57 \\
\hline CV & 7,78 & 16,93 & 2,08 & 7,68 & 6,72 & 15,36 & 7,67 & 18,34 \\
MG & 82,98 & 27,53 & 89,17 & 46,34 & 7,64 & 7,11 & 5,13 & 4,13 \\
\hline
\end{tabular}

** Significativo a $1 \%$ de probabilidade pelo teste F; * Significativo a 5\% de probabilidade pelo teste F; ns Não significativo pelo teste F; QM: Quadrado médio; FV: Fator de variação; CV: Coeficiente de variação; MG: Média geral; VA: vigor automático; C: índice de crescimento; U: índice de uniformidade; VM: vigor manual; CP: comprimento de plântula por medição manual; GE CP: comprimento de plântula via GroundEye; CR: comprimento de raiz por medição manual; GE CR: comprimento de raiz via GroundEye. 
ANEXO C - Análise de variância da interação entre teste manual e teste via GroundEye de oito lotes de sementes de soja das variedades 1 e 2, Brasília-DF, 2017.

Anexo C1. Análise de variância da interação entre teste manual e teste via GroundEye de oito lotes de sementes de soja da variedade 1, Brasília-DF, 2017.

\begin{tabular}{lccc}
\hline \multicolumn{1}{c}{ FV } & EA x VA & CP x GE CP & CR x GE CR \\
\hline Lotes & $586.08^{* *}$ & $11.25^{* *}$ & $4.00^{* *}$ \\
Teste & $1.07 \mathrm{~ns}$ & $0.75 \mathrm{~ns}$ & $6.94^{* *}$ \\
Lotes x testes & $22.50 \mathrm{~ns}$ & $0.17 \mathrm{~ns}$ & $0.15 \mathrm{~ns}$ \\
Resíduo & 39.25 & 0.28 & 0.14 \\
\hline CV & 7.15 & 6.83 & 7.91 \\
\hline Média & 87.68 & 7.78 & 4.79
\end{tabular}

** Significativo a $1 \%$ de probabilidade pelo teste F; * Significativo a $5 \%$ de probabilidade pelo teste F; ns Não significativo pelo teste F; QM: Quadrado médio; FV: Fator de variação; CV: Coeficiente de variação; MG: Média geral; EA:

Envelhecimento acelerado; VA: vigor automático; CP: comprimento de plântula por medição manual; GE CP: comprimento de plântula via GroundEye; CR: comprimento de raiz por medição manual; GE CR: comprimento de raiz via GroundEye.

Anexo C2. Análise de variância da interação entre teste manual e teste via GroundEye de oito lotes de sementes de soja da variedade 2, Brasília-DF, 2017.

\begin{tabular}{|c|c|c|c|}
\hline & \multicolumn{3}{|c|}{ QM } \\
\hline FV & EA x VA & CP x GE CP & CR x GE CR \\
\hline Lotes & $504.84 * *$ & $3.44 * *$ & $1.73 * *$ \\
\hline Teste & $7.20 \mathrm{~ns}$ & $4.36 * *$ & $16.17 * *$ \\
\hline Lotes $\mathrm{x}$ testes & $21.56 \mathrm{~ns}$ & $0.33 \mathrm{~ns}$ & $0.09 \mathrm{~ns}$ \\
\hline Resíduo & 40.71 & 0.27 & 0.17 \\
\hline $\mathrm{CV}$ & 7.72 & 7.11 & 8.95 \\
\hline Média & 82.64 & 7.37 & 4.63 \\
\hline
\end{tabular}

